\title{
LEADERSHIP VISION AND SCHOOL-FAMILY-COMMUNITY PARTNERSHIPS IN THE MODEL SCHOOLS FOR INNER CITIES INITIATIVE: \\ A MULTIPLE EXPLANATORY CASE STUDY
}

By

\begin{abstract}
Natalie Cummins
Bachelor of Arts (Early Childhood Studies), Ryerson University, 2014

Master in Environmental Studies, York University, 2017
\end{abstract}

\author{
An MRP \\ presented to Ryerson University \\ in partial fulfillment of the \\ requirements for the degree of \\ Master of Arts \\ in the program of \\ Early Childhood Studies
}

Toronto, Ontario, Canada, 2020

(C) Natalie Cummins, 2020 


\begin{abstract}
AUTHOR'S DECLARATION
I hereby declare that I am the sole author of this MRP. This is a true copy of the MRP, including any required final revisions.
\end{abstract}

I authorize Ryerson University to lend this MRP to other institutions or individuals for the purpose of scholarly research

I further authorize Ryerson University to reproduce this MRP by photocopying or by other means, in total or in part, at the request of other institutions or individuals for the purpose of scholarly research.

I understand that my MRP may be made electronically available to the public. 


\begin{abstract}
Leadership Vision and School-Family-Community Partnerships in the Model Schools for Inner Cities Initiative: A Multiple Explanatory Case Study

Master of Arts, 2020

Natalie Cummins

Early Childhood Studies, Ryerson University

Research has highlighted the important role of school leadership in fostering school-familycommunity partnerships, but few studies purposefully test causal links between leadership practices, partnerships, and student educational success and family well-being. This explanatory multiple case study analyzed secondary parent focus group and school administrator interview data at two schools in the Toronto-based Model Schools for Inner Cities initiative. Descriptive analyses revealed seven leadership practices administrators used to foster school-familycommunity partnerships. Explanatory analyses considered how and through what mechanisms of change leaders who share leadership responsibilities with families affect student and family outcomes. A causal link between shared leadership strategies and student and family outcomes was confirmed. Key mechanisms of change included parents' sense of ownership and feelings of empowerment as well as parents' perceptions of congruent interests and goals. Further, moderating conditions were identified, most predominantly, the leader's social justice vision. Implications for future research and practice are discussed.
\end{abstract}




\section{ACKNOWLEDGEMENTS}

A heartfelt thank you to the families, school staff, and Toronto District School Board partners who shared their time, voices, and input to create this piece. Thank you to the research members and partners of the Greater Equity in Early Education and Care research team for your ongoing support.

Thank you to Dr. Sejal Patel, my supervisor and cheerleader. Thank you for your unwavering encouragement, mentorship, and companionship since we began our work together some time ago, at the beginning of my undergraduate degree.

Thank you to Dr. Kathryn Underwood, my second reader, for your important and necessary questions and reviews that encouraged me to continue to pause and reflect.

Thank you to Dr. Susan Jagger for providing me with the space for needed wondering and wandering while completing this work.

Thank you to my family, friends, and loves. To MJ and OC for the countless dinners and debriefs. To HR and MR for our walks and wanderings.

This research was partially funded by a Social Sciences and Humanities Research Council of Canada Partnership Engage Grant awarded to Dr. Sejal Patel. 


\section{TABLE OF CONTENTS}

ABSTRACT III

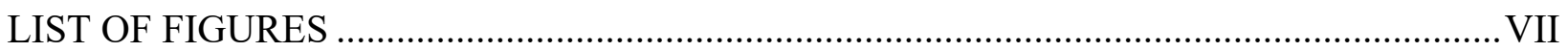

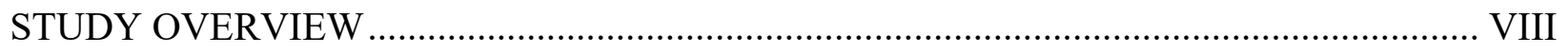

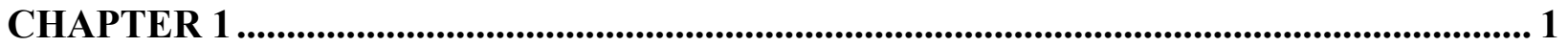

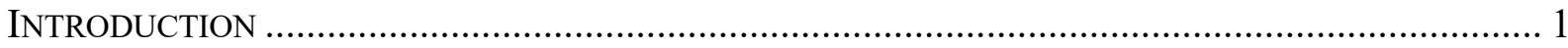

Connecting School-Family-Community Partnerships with Parent Engagement and Other

Student, Family, and Community Outcomes.............................................................. 3

School Leadership Strategies and Mechanisms of Change in School-Family-Community

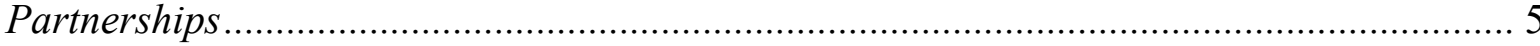

Moderating Conditions Influencing Leadership Practices that Foster School-Family-

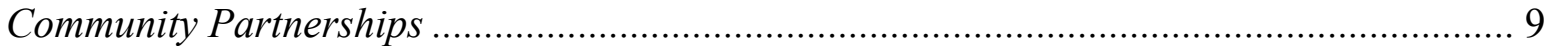

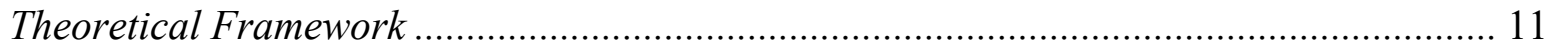

The Present Study .................................................................................................. 13

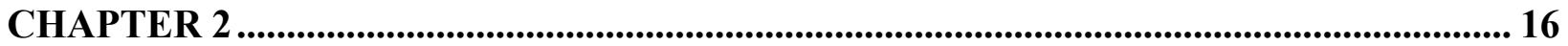

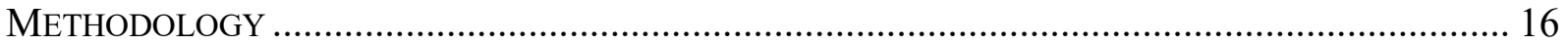

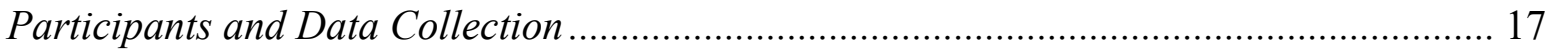

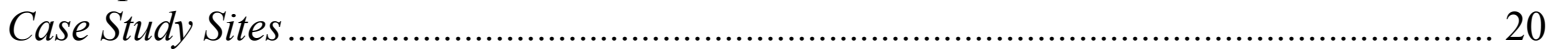

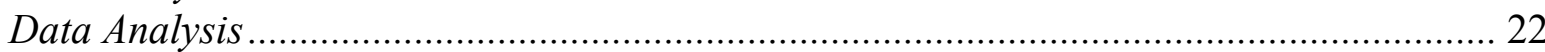

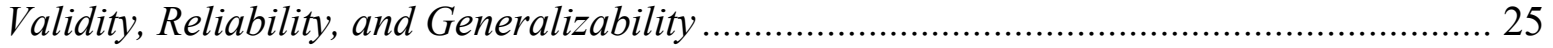

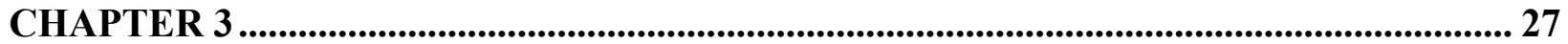

RESULTS AND DISCUSSION: DESCRIPTIVE ANALYSIS............................................................ 27

(1) Creating a Welcoming Physical and Social School Environment ........................... 28

(2) Fostering a Culture of Care ................................................................................ 30

(3) Communication with Families ........................................................................... 33

(4) Encouraging Parent Leadership and Advocacy .............................................. 36

(5) Leadership Presence in the Community.................................................................. 38

(6) Establishing the School as a Social and Cultural Broker....................................... 40

(7) Leveraging Community Partnerships and Administrators' Personal Social Capital to

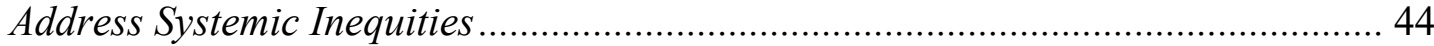

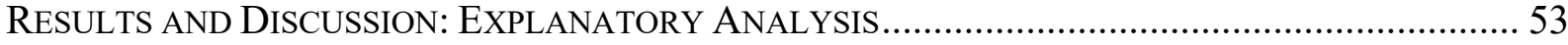

Defining Context, Mechanism of Change, and Outcome.............................................. 55

Hypothesis 1: School Staff and Families Feeling a Collective Sense of Ownership and Investment in Family and Community Well-being......................................................... 56 Hypothesis 2: Families Perceiving a Lack of Mutually Shared Goals Between School Staff

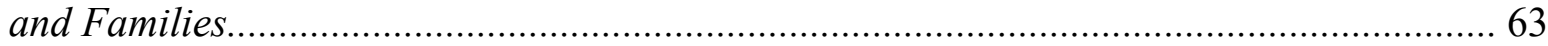
Hypothesis 3: Families Feeling Empowered and a Sense of Self-Efficacy ....................... 74

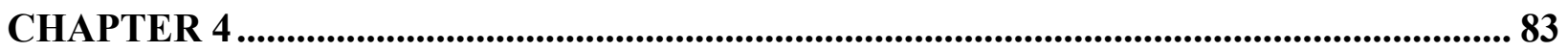

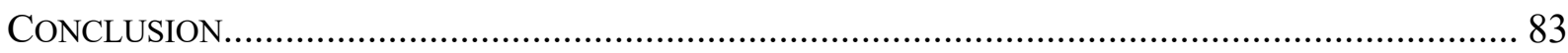

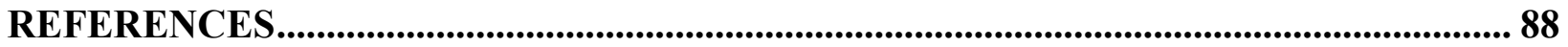




\section{LIST OF TABLES}

Table 1. MS1 and MS2 Parent Focus Group and Administrator Interview Participants.........17

Table 2. Transcripts (Focus Groups and Interviews) Analyzed.............................18

Table 3. Explanatory Analysis Process ................................................23 


\section{LIST OF FIGURES}

Figure 1. Conceptualization of the Hypothesized Causal Chain of Events......................55 


\section{Study Overview}

The important role of school leadership in fostering school-family-community partnerships has been documented in research through largely descriptive, qualitative studies. These studies highlight key leadership practices, strategies or styles that are thought to lead to improved partnerships, but few purposefully test the causal links between leadership practices, school-family-community partnerships, and student educational success and family well-being. The present explanatory multiple case study analyzed secondary school administrator interview and parent focus group data collected in 2014 and 2019 from two schools in Toronto that are part of the Model Schools for Inner Cities initiative. This study is part of a larger communitypartnered research project led by Dr. Sejal Patel (Early Childhood Studies, Ryerson University, principal investigator) that I have worked on as a research assistant and project manager for several years. This analysis took place in two phases. The first descriptive analysis phase aimed to discover the practices and strategies used by leaders at the two school sites to foster schoolfamily-community partnerships and revealed the following seven key practices and strategies: (1) creating a welcoming physical and social school environment, (2) fostering a culture of care,

(3) communication with families, (4) encouraging parent leadership and advocacy, (5) leadership presence in the community, (6) establishing the school as a social and cultural brokerage, and (7) leveraging community partnerships and administrator's personal social capital to address systemic inequities. The second explanatory analysis phase aimed to discover how, and through what mechanisms of change, do leaders with a social justice vision who collaborate and share leadership responsibilities with families affect student family well-being and educational success. This explanatory analysis confirmed the link between shared leadership practices and student and family outcomes. Key mechanisms of change that linked shared leadership practices 
and improvements in family well-being and student educational success included families' feelings of a sense of ownership and investment in the school and community and families' feelings of empowerment. Conversely, it was found that when shared leadership practices are diminished, families' perceptions of a lack of congruent school, family, and community interests and goals is a key mechanism of change leading to decreased parent engagement in school and negative impacts on family well-being and student educational success. The explanatory analysis clarified key conditions that moderated these pathways, including the leader's vision of and attitudes towards social justice, the school's history of family and community engagement, community context, staff turnover, as well as the administrator's attitude towards parent and community engagement.

The voices and stories of families and school leaders in the Model Schools for Inner Cities initiative shared in the present study come at a time of increasing advocacy for antiracism, anti-oppression, and justice in systems, like education, that reproduce classism, racism, ableism, and social inequities. Informed by critical pedagogy and a place-based perspective, this study has implications for school-family-community partnership practices, school leadership strategies in marginalized communities, system-level decision-making about the distribution of services and resources for students and families, and ultimately, how schools and education systems can create more equitable schools and communities. 


\section{CHAPTER 1}

\section{Introduction}

For the last two decades, in an effort to improve student outcomes and reduce educational inequities, there have been a myriad of school-based initiatives, reforms, and programs that strive to expand the role of the school to not only support student academic achievement and wellbeing, but also family and community well-being. These programs can be found in North America with initiatives such as Full-Service Community Schools (Dryfoos, 1994; Dryfoos, 2002; Salm et al. 2016), Schools of the $21^{\text {st }}$ Century (Finn-Stevenson \& Zigler, 1999; Henrich et al., 2006; Zigler \& Finn-Stevenson, 2007), Comer School Development Program (Comer \& Emmons, 2006; Cook et al., 2000; Haynes, 1996), Toronto First Duty (Corter \& Pelletier, 2010; Corter et al., 2012; Pelletier \& Corter, 2005), in Europe with initiatives such as Full-Service Extended Schools (Cummings et al., 2005; Department for Education and Skills United Kingdom, 2004; Raffo \& Dyson, 2007) and the Extended Schools Programme (Department of Education Northern Ireland; 2012; Department of Education Northern Ireland, 2019; McGill, 2011), and worldwide (e.g., Vensterschools, Doornenbal \& Kruiter, 2016). Sometimes called 'community schools', 'full-service schools', or 'schools as community hubs', these initiatives

often include a concerted effort to increase family and community engagement in schools and offer integrated social and health services to meet the broad needs of the families and communities they serve. The underlying assumption of such programs is that improving the wellbeing of families and communities improves student educational success and overall well-being. Indeed, previous research has suggested that when schools take concerted efforts to establish school-family-community partnerships, this can lead to improvements in students' academic achievement, well-being, and school attendance (e.g., Caldas et al. 2019; Durham et al., 2019; 
Patel et al., 2016), can improve family-school relations and parent engagement (Khalifa, 2012; Patel \& Corter, 2013), and can have implications for community development (Green, 2015). Over the years, researchers have noted the vital importance of school leadership in establishing these school-family-community partnerships (e.g., Auerbach, 2010; Epstein et al., 2011; Van Voorhis \& Sheldon, 2004). School leaders have been found to be essential in setting the tone and culture of school-family-community partnerships (Barr \& Saltmarch, 2014), in maintaining and sustaining school-community service partnerships (Muijs, 2007; Sanders, 2016), in developing reciprocal and trusting school-family relations (FitzGerald \& Quiñones, 2019; Krumm \& Curry, 2017), and can act as a catalyst to their school's active involvement in combatting inequities faced by children, families, and communities (Green, 2018). These largely exploratory and descriptive studies have made invaluable contributions to our understandings of the role of leadership in school-family-community partnerships by describing leadership practices that contribute to strong partnerships. There has been less research, though, that takes up explanatory methods to explain exactly how or through what mechanisms of change these leadership practices lead to improved outcomes for students, families, and communities. As noted by Epstein (2011) more confirmatory studies that consider "how full programs and specific practices of school, family, and community partnerships develop and affect families and students" (p. 58, emphasis added) are needed. Epstein (2011) calls for more research on the particular pathways and mechanisms that connect school-family-community partnership activities with family and community engagement and outcomes for students, families, and communities. The present study aims to address Epstein's (2011) call by using a multiple explanatory case study method to investigate how the leadership practices used by two elementary school administrators to foster school-family-community partnerships affected student academic success and family well-being. 
A review of literature reveals that although there is scholarship on school-family-community partnerships, leadership, and some associated outcomes, there is significantly less research that identifies the mechanisms of change that connect particular school-family-community partnership and leadership strategies with specific results for students, families and communities.

\section{Connecting School-Family-Community Partnerships with Parent Engagement and Other}

\section{Student, Family, and Community Outcomes}

As the definition of school-family-community partnerships has expanded overtime, so has our understanding of the benefits and outcomes of these partnerships. Literature on schoolfamily-community partnerships has evolved from primarily focusing on a narrow, school-centric conception of parent engagement where parents are physically involved in the day-to-day activities of the school. For example, this might be through volunteering in the school building or overseeing students' homework, (e.g., Epstein \& Becker, 1982; Hoover-Dempsey \& Sandler, 1997) to a more bi-directional understanding of school-family-community engagement, where schools, families and communities are engaged and communicate with one another in varying and diverse ways (e.g., Auerbach, 2010; Epstein, 2011; Patel et al., 2008; Valli et al., 2016). For example, Epstein (2011) conceptualizes school-family-community partnerships as existing in overlapping spheres where partnerships between groups are built on reciprocity and mutual goals. In school-family-community partnerships, families, community organizations, and schools collaborate with the shared goal of enhancing the well-being of students, families, and community members. Historically the literature considering the benefits of school-familycommunity partnerships has been primarily focused on school- and student-focused outcomes (e.g., Ice \& Hoover-Dempsey, 2011; Jeynes, 2007). Researchers have documented improvements in student attendance (Sheldon, 2007), decreased numbers of student suspensions (Sheldon \& 
Epstein, 2002), and a greater chance of graduation amongst high school students (Caldas et al., 2019) as a result of school-family-community partnerships. Other research has shown that as schools adopt school-family-community partnership initiatives, parent and community engagement in school increases (López et al., 2001; Medina et al., 2019; Patel \& Corter, 2013), and in turn student academic success improves (Epstein, 1995; Jeynes, 2007; Sheldon \& Epstein, 2005; Jeynes, 2005). There is movement towards and advocacy for a broader view of the potential benefits of partnerships that include social, educational, and health related outcomes for students, families, and the broader community, such as increased parent and community member social capital (Newton et al., 2017), parent educational attainment (López et al., 2001), parents' feelings of self-efficacy (Patel \& Corter, 2013), and family and community health and well-being (Green, 2015; Medina et al., 2019). Although this literature helps to identify some outcomes associated with school-family-community partnerships, few discuss the exact mechanisms through which these partnerships lead to specific outcomes. For example, one study led by Sheldon (2005) used structural equation modelling analyses of survey data collected at schools with school-wide school-family-community partnership programs and found that schools with higher quality partnerships had more parent engagement. This effect was mediated by support for partnership programs from school staff, parents, and community members. Even less research considers the role of school-level leadership in these causal pathways (e.g., Fuller et al., 2013; Epstein, 2011). For example, Epstein's et al. (2011) analysis of survey data from 407 schools across 15 states found that school-level leader support for partnership programs predicted the quality of program implementation and outreach; however, the study does not examine student and family outcomes. Turning to literature on the important role of school-level leadership 
reveals some indication of mechanisms of change that might be at play in the relationship between school-family-community partnerships and student and family outcomes.

\section{School Leadership Strategies and Mechanisms of Change in School-Family-Community Partnerships}

Previous researchers have narrowed in on the importance of school leadership in fostering school-families-community partnerships. Although not explicitly looking for mechanisms of change, these mostly exploratory, descriptive studies of effective leadership practices in schoolfamily-community partnerships point towards some potential mechanism connecting leadership practices in school-family-community partnerships to student, family, and community outcomes. This research emphasizes the importance of a shared leadership approach, developing trusting reciprocal relations with families and communities, and leaders acting in solidarity with families and communities to address community concerns.

Researchers who investigate shared leadership in school-family-community partnerships stress the importance of having school leaders who share school decision-making power and leadership responsibilities with parents, school staff, and community members. Sometimes called cross-boundary leadership (Adams, 2019; Adams and Jean-Marie, 2011; Krumm \& Curry, 2017), distributed leadership (Fuller et al., 2013), or democratic partnerships (FitzGerald \& Quiñones, 2019), these practices are focused on reducing power hierarchies in schools (where school staff are considered experts and hold decision-making power over families and communities) by creating opportunities for student, families, and communities to engage in democratic dialogue (FitzGerald \& Quiñones, 2019; Ishimaru, 2018) and collaborative decisionmaking in order to set the direction of the school's activities and services (Peterson \& Durrant, 2013). Researchers have cited examples of leaders, parents, and communities collaborating and 
sharing leadership responsibilities through parent councils (FitzGerald \& Quiñones, 2019), through parents leading and hosting school-family-community meetings (Ishimaru, 2013), and through having frequent, informal events for parents and community members to discuss topics important to them (Auerbach, 2010). Although researchers have suggested these practices lead to mechanisms of change for parents where they feel more empowered and a greater sense of ownership, investment, and sense of belonging in the school (Quiñones \& FitzGerald, 2019; Ishimaru, 2013), which in turn may make parents feel more comfortable in engaging in the school and their child's academics, no studies have purposefully tested for these pathways of change.

Other researchers have investigated the role of leadership in setting the partnership tone of the school by establishing trusting and reciprocal relationships with families and the community. Parents feeling a sense of trust in their relationships with the school may be an important mechanism of change, as it has been found in a number of studies to be key in schoolfamily-community partnerships and an important factor in determining how welcomed and comfortable parents feel being involved in the school (Barr \& Saltmarch, 2014; Bryk \& Schneider, 2002; FitzGerald \& Quiñones, 2019). Building trust is not only the responsibility of principals, but can include other school staff, such as community school coordinators (schoolsupport staff who lead and facilitate partnerships between the school and community), who can also play integral leadership roles in building trust with families (FitzGerald \& Quiñones, 2018; Ishimaru et al., 2016). FitzGerald and Quiñones (2018) found that community school coordinators facilitated conversations between school staff and families and acted as someone families could turn to for support, which made families feel they could trust the school and in turn made families feel more comfortable in the school. Khalifa's (2012) ethnographic study of 
leadership at an urban high school in the United States of America (USA) found that strategies leaders used to build trust and rapport with families and communities included the principal being visibly present and involved in the local community, sharing and addressing family and community concerns (for example, through supporting organized community protests), and engaging in frequent personal exchanges at the school and in home visits with students and parents about family, community, and personal issues. Khalifa (2012) calls leaders who take on these leadership practices where community-oriented goals are at the center of their work 'community leaders' and claims that these practices led to greater parent engagement. But, Khalifa (2012) and others do not intentionally test for the mechanisms of change that might explain this connection. Alongside Khalifa's (2012) work there is a growing body of literature that focuses on the ways that school leaders partner with families and communities to coadvocate for community causes and create systemic change (e.g., Auerbach, 2010; Fitzgerald \& Quiñones, 2018; Green, 2015; Green, 2018; Ishimaru, 2013; Ishimaru, 2018). Research on these community-oriented practices suggests that having mutually shared goals and interests to create change could act as mechanisms of change leading to improved outcomes for families. For example, in interviews with principals and school staff at two urban high schools in the USA undergoing school reform and simultaneous community revitalization, Green (2018) identified several practices school leaders enacted to link their school reform to community concerns. In one example, the principal leveraged community partnerships to fill health service gaps in the local community by offering a school-based clinic for the community. Green $(2015 ; 2018)$, among others (Galindo et al., 2017; Newton et al., 2017), explore how school leaders establish partnerships with community organizations to establish the school as a social and cultural brokers (Green, 2018; Ishimaru et al., 2016) that link families and community members to 
services that may increase families' social and cultural capital. Green (2018) draws from social capital theory (Coleman, 1988) and Chaskin's et al. (2001) 'organizational brokers' to define a social broker as a place in a community that acts as a link between different organizations and services that together build individual, family, and community capacity. A cultural broker refers to what Lopez and Stack (2001) call a 'cultural bridge', meaning, an individual or organization that acts as an intermediary between two or more social groups of people in order to help families and community members decode, translate, and navigate networks in the dominant culture of power and social systems, while "integrating and affirming community cultural values, resources, and rights" (p. 48). For example, staff might assist newcomer and/or refugee families in navigating and accessing settlement, education, social, or health services (Yohani, 2011). These studies do not explicitly discuss how establishing schools as social or cultural brokers lead to improved outcomes for students, families, and communities. However, Fitzgerald and Quiñones (2019) suggest that principals who create opportunities for social and cultural brokering in their schools and leverage partnerships with community organizations to address community concerns, may lead parents' to feel that the school, family, and community have mutually shared goals and interests.

Ishimaru (2013) cautions, though, against viewing principals as a community 'heroes' and instead speaks to the ways that leaders can be thought of as community organizers who empower and support community- and family-driven change. Through what Ishimaru (2019; 2020) calls equitable collaboration, leaders can act as co-advocates for community causes by building parents' capacity to navigate, advocate and create change within social and educational systems, by building cross-sector partnerships with community organizations and establishing families and community members as experts and leaders in school and community initiatives. 
Equitable collaborations can be built on acting in solidarity with nondominant families

(Ishimaru, 2020) and marginalized communities (Ishimaru, 2019; Ishimaru, 2020). Ishimaru (2013) suggests that these collaborations can lead to parents feeling empowered and a sense of collective ownership over the school and community (Ishimaru, 2013). Still, more research is needed to define the pathways through which schools advocating with communities to address community concerns, either through equitable collaborations or establishing the school as a social and cultural broker, leads to improved outcomes for children, families, and communities.

\section{Moderating Conditions Influencing Leadership Practices that Foster School-Family- Community Partnerships}

Literature on leadership and school-family-community partnerships also reveals some potential moderating conditions that may influence the effectiveness of particular leadership practices that foster school-family-community partnerships. Principal attitude towards school and community partnerships (Muijs, 2007), principals' social capital (Sanders, 2016), principal racial, cultural, and linguistic identity (Hernandez et al., 2014; Quiñones and FitzGerald, 2019; Shah, 2018a), and principal social justice stance (Hernandez et al., 2014) may influence the quality and types of school-family-community partnerships. For example, a multiple case study of three Full-Service Community Schools in the USA revealed that principals who had strong social ties to school districts and city leaders were able to leverage their social capital to secure funding and resources in ways principals with less social ties could (Sanders, 2016). In a study of the motivations of an exemplar Latina leader who fostered positive school-family-community partnerships, Hernandez et al. (2014) found that the leader sharing her racial and cultural identities with students and families helped her to have a better understanding of students' and families' lived experiences. Hernandez et al. (2014) found that through her lived experience the 
leader was more aware of the discrimination and racialization experienced by members of their school community, and was more willing to act as an ally to and co-advocate with families for community causes. This principal's racial identity and lived experiences as a Latina woman also played a role in her capacity to act as a social justice leader (Hernandez et al., 2014). In the context of the Toronto District School Board, Shah (2018a) found that school administrators' white privilege played a role in how they enacted social justice leadership. Although principals were committed to inclusive practices and advocated for greater equity for their students, their awareness of their complicity in and the effects of their white privilege varied (Shah, 2018a). Social justice leadership has been defined by Theoharis (2007) as leaders who, "make issues of race, class, gender, disability, sexual orientation, and other historically and currently marginalizing conditions... central to their advocacy, leadership practice, and vision" (p. 223) and actively work to eliminate social inequities in their schools and communities (Theoharis, 2007). Researchers have described some of the strategies and approaches that social justice leaders have enacted to create more just schools and communities such as establishing a school culture that rejects deficit-based assumptions about students' and communities' abilities (DeMatthews et al., 2016; Riester et al., 2002), removing pull-out segregation and streaming programs to resist educational inequalities (Theoharis, 2007; Theoharis \& O’Toole, 2011), and seeking input from community members about needed supports and services (Goldfarb \& Grinberg, 2002). For each of these studies, the social justice stance of the leader was an essential condition for establishing successful school-family-community partnership that enhance equity in their children, families, and communities. Although these studies have helped to shed light on some of the conditions under which effective school-family-community partnerships can flourish, more research is needed to uncover how these leadership characteristics might moderate 
or influence the relationship between leadership practices in school-family-community partnerships and student, family, and community outcomes. This study aims to identify the moderating conditions, like a social justice leadership stance, and the mechanisms of change in the relationship between school-family-community partnerships and student educational success and family well-being.

\section{Theoretical Framework}

The theoretical frameworks guiding my research include critical pedagogy and a placebased perspective. Critical pedagogy has developed overtime from the work of authors such as Freire (1970, 1973), Giroux (1988), Burbules and Berk (1999), and bell hooks (1994). Critical pedagogy begins with the assumption that society is fundamentally built on structural injustices and inequities that result from unequal power relations in established class, racial, and cultural social hierarchies (Burbules \& Berk, 1999). These societal injustices and inequities are perpetuated through social institutions, such as education. A critical pedagogy strives for both educators and students to recognize these inequities and actively work to confront, challenge, and dismantle them (Burbules \& Berk, 1999; Gruenewald, 2003). For example, hooks (1994) discusses how educators hold positions of power and can use that position to elevate the voices of students from nondominant classes and races. For Freire (1970), although educational institutions perpetuate oppression of nondominant groups, they are also places where educators and students can reach what he called conscientização, or a critical consciousness, where educators and students learn to recognize and name societal inequities and take action for social justice. Giroux (1988) too argued for the transformative potential of schools, where schools can and should strive to create a more just society. Gruenewald (2003), who was inspired by Haymes' (1995) work on a pedagogy of place in the inner city, suggests a connection between 
critical pedagogy and a place-based perspective. While critical pedagogy encourages educators and students to recognize, challenge, and change societal inequities, a placed-based perspective draws from land-based pedagogy's and environmental education's emphasis on education that is focused on students' local environments and contexts. A critical place-based perspective encourages a thoughtful consideration of a school's local community, its history, and the sociocultural context in which education takes place (Gruenewald, 2003). In a critical place-based perspective, educational content, pedagogy, and school activities are relevant and responsive to the lived experience and social and cultural political context of students, families, and their local communities (Gruenewald, 2003). For example, Kerr et al. (2014) discuss how initiatives that aim to improve educational and social outcomes for students and families, whether led by government, school boards, or communities, must take a local, place-based approach in order to effectively address the unique socio-economic conditions of their local communities. Kerr et al. (2014), argue that interventions that target marginalized groups must to shift away from emphasising decontextualized, one-size-fits-all solutions towards a focus on customized interventions that respond to the unique strengths and challenges of each community.

In coupling critical pedagogy and a place-based perspective, I research the topic of leadership and school-family-community partnerships in inner-city schools through a lens that recognizes the school as an institution that perpetuates inequities and injustices, and yet also has the potential to resist dominant status quo class, racial, ability, and cultural hierarchies. These acts of resistance are contextualized by the places (i.e., schools, communities) in which they are enacted. 


\section{The Present Study}

The present study addresses Epstein's (2011) call for more confirmatory studies on school-family-community partnerships by using a multiple explanatory case study method to investigate how particular leadership strategies to fostered school-family-community partnerships affected student academic success and family well-being at two case study sites. The focal context of the study is situated in two schools that are part of the Model Schools for Inner Cities (MSIC) Initiative, a Toronto-based initiative in Canada that aims to establish schools as the heart of the community through school-family-community partnerships (Toronto District School Board [TDSB], 2016). Specifically, this study will explain how school administrators with a vision of social justice who collaborate and share leadership responsibilities with families affect family well-being and students' educational success.

\section{Context: The Model Schools for Inner Cities Initiative}

In 2005, the TDSB's Inner City Task Force proposed a systematic approach to address the socio-economic challenges experienced by families living in inner-city neighbourhoods that impact student academic achievement and well-being (TDSB, 2005). In 2006 the MSIC initiative began and aimed to "level the playing field" for students in Toronto by providing elementary schools in the highest-needs neighbourhoods additional school funding, services, and resources (TDSB, 2016, p. 2). The MSIC initiative started in three schools in the Toronto area in 2006-7 and grew to serve 150 schools by 2012-13. The MSIC program takes a multi-pronged, comprehensive approach to supporting the whole child (Yau, et al., 2018). The MSIC initiative aims to close "the opportunity gap to support equitable outcomes for all students" by increasing children and families' access to a variety of resources, services, and opportunities through their school (TDSB, 2016, p.1). The MSIC initiative is guided by 5 essential components: 
1. "Innovation in teaching and learning practice and in school structure"

2. "Support services to meet student's physical, social, and emotional needs"

3. "School as heart of the community"

4. "Research, review, and evaluation of students and programs"

5. "Commitment to share successful practices" (Yau, et al., 2018, p. 2)

The current research study will focus on the MSIC initiative's second and third essential components, 'the school as heart of the community' and 'support services for students and families' (TDSB, 2005). Some features that make schools in the MSIC initiative the 'heart of the community' include outreach programs to engage families and community members in schools, active parent councils, school and community partnerships to provide recreation, health, and social services to students, and the inclusion of a MSIC Community Support Worker in each school (MSIC Community Support Workers act as a liaison between the school and community) (e.g., TDSB, 2016). Schools in the MSIC initiative offer family drop-in programs open to families in the community for children from birth to six years of age (Yau et al., 2012), afterschool programming for students (Yau, Archer, et al., 2015), breakfast, lunch and snack nutrition programs for students offered for free or at reduced costs (TDSB, 2016), and a few schools offer in-school clinics (Yau, De Jesus, et al., 2015). Schools in the MSIC initiative partner with local agencies to offer programs and services that meet the unique needs of their communities. The MSIC initiative's aim is to provide schools with an equitable distribution of programs and services with the understanding that every community has varying strengths and needs. With this in mind, the MSIC initiative looks different in each model school. The types of services, programs, and supports offered are unique to each school community (Yau et al., 2018). 


\section{Research Questions}

A review of the literature reveals that although there is research that attests to the importance of leadership in school-family-community partnerships by highlighting specific promising leadership practices, there is a lack of research that investigates how these leadership practices lead to improved outcomes for students and families. Further, while there are numerous internal TDSB research reports on the MSIC initiative and associated programs (e.g., Yau \& Romard, 2016; Yau et al., 2013; Yau et al., 2018), there is limited published scholarly literature on the MSIC initiative (e.g., Cohen-Silver et al., 2017; Shah, 2018b). While Shah (2018a) has written about social justice leadership within the TDSB, her descriptive study focused on the role that principals' white, middle class identities played in their enactment of social justice leadership. This explanatory case study investigated how the leadership practices used by school leaders to foster school-family-community partnerships at two elementary schools in the MSIC initiative in Toronto affects family well-being and student educational success through a secondary data analysis of school leader interview data and parent focus group data collected in 2014 and 2019. In this study, a descriptive analysis of the data later informed an explanatory analysis of the data, guided by the following research questions:

(1) Within the context of the MSIC initiative in Toronto, Canada, what leadership strategies and practices do school administrators use to foster school-family-community partnerships?

(2) Within the context of the MSIC initiative in Toronto, Canada, how do school leaders with a social justice vision who collaborate and share leadership responsibilities with families affect family well-being and student educational success? 


\section{CHAPTER 2}

\section{Methodology}

This multiple explanatory case study included a secondary qualitative analysis of parent and administrator data from two elementary schools in the MSIC initiative. Case study research helps to clarify the real-life experiences of research participants and the complex contextual conditions of a social phenomenon through deep investigation (Yin, 2018). Multiple case studies provide researchers with an opportunity to compare and contrast results at two or more case study sites in order to gain a more in-depth understanding of complex phenomenon (Yin, 2009). Explanatory case studies are useful when trying to explain the 'how' of social phenomena (Yin, 2018). The explanatory analysis in the present study sought to gain a deeper understanding of how, and through what mechanisms of change, the school-family-community engagement practices used by school administrative leadership with a vision of social justice, affect family well-being and student educational success.

This study used an anonymous secondary data set from a larger community-engaged research project led by Dr. Sejal Patel (Early Childhood Studies, Ryerson University, principal investigator) that has ethical approval from Ryerson University’s Research Ethics Board. Dr. Patel granted access to transcripts and field notes of 8 focus groups and 4 interviews to conduct the secondary data analysis. Although conducting a secondary analysis often places researchers at an additional distance from the research and the participants, I have worked with Dr. Patel on this larger project for several years as a research assistant and research project manager. As a research assistant on her team, I was present for some of the data collection analyzed here. This was advantageous in my analyses, in that I had knowledge of the history of the research project and an understanding of contextual features of the school, community, and data collection 
process. Throughout the analysis of this secondary data I met with Dr. Patel and research community partners who led and facilitated the primary data collection in the larger research project. As noted by Muhammad et al. (2015), the membership of the research team matters and has implications for how teams collectively confront social inequities in research. I recognize that my white, middle-class, privileged identity and positions as an Early Childhood Educator and community-engaged researcher shapes the ways in which I interpreted, analyzed, and represented the data in the present study. Frequent meetings with the research team throughout these analyses, a team comprised of first and second generation newcomers and women of colour, provided the opportunity to discuss the data and analysis procedures as well as continuously reflect on how my orientation to the research shaped the knowledge creation in the present study. These opportunities for contextualizing the data and ongoing reflexivity helped to maintain a focus on the voices of the participants.

\section{Participants and Data Collection}

This secondary analysis includes parent ${ }^{1}$ focus group and administrator interview data collected at two MSIC schools (Model School 1 [MS1] and Model School 2 [MS2]) in 2014 and in 2019 in Toronto, Canada. See Table 1 for a description of the number of participants in the sample and Table 2 for a description of the number of transcripts analyzed.

\section{Table 1}

MS1 and MS2 Parent Focus Group and Administrator Interview Participants

\begin{tabular}{ccccc}
\hline Year & $\begin{array}{c}\text { MS 1 Parents } \\
(n=23)\end{array}$ & $\begin{array}{c}\text { MS2 Parents } \\
(n=36)\end{array}$ & $\begin{array}{c}\text { MS1 School } \\
\text { Administrators } \\
(n=3)\end{array}$ & $\begin{array}{c}\text { MS2 School } \\
\text { Administrators } \\
(n=4)\end{array}$ \\
\hline 2014 & 18 & 29 & 2 & 2 \\
\hline 2019 & 5 & 7 & 1 & 2 \\
\hline
\end{tabular}

\footnotetext{
${ }^{1}$ The term parent refers to any legal or non-legal, related or unrelated guardian responsible for the care of a child (TDSB, 2008) who was attending the school at the time of the focus group.
} 
Table 2

Transcripts (Focus Groups and Interviews) Analyzed

\begin{tabular}{lcc}
\hline & 2014 & 2019 \\
\hline MS1 Parent Focus Group & 2 & 1 \\
\hline MS1 Administrator Interview & 1 & 1 \\
\hline MS2 Parent Focus Group & 4 & 1 \\
\hline MS2 Administrator Interview & 1 & 2 \\
\hline
\end{tabular}

Semi-structured focus groups and interviews were conducted in both 2014 and 2019. The predetermined questions acted as a general guide for topics of discussion in data collection, but the semi-structured nature permitted researchers to follow new directions in the conversation that opened up during the conversation (Kvale, 2007).

In both 2014 and 2019, parents and administrators were asked questions about programs and services available to children and families at the school, school-family relationships, family engagement, and the ways that the school acts as the hub of the community. A noteworthy difference between 2014 and 2019 focus group and interview questions relevant to this analysis was the addition of a question in 2019 asking specifically about family engagement of newcomer, refugee, and culturally diverse families.

\section{Parents}

At each school site in 2014 parents could participate in focus groups conducted either at the school site or in another community location. At MS1 in 2014, one school-based parent focus group and one community-based focus group were conducted with a total of 23 parents. At MS2 in 2014, two school-based parent focus groups and two community-based parent focus groups were conducted with a total of 29 parents. Two locations were offered to families to participate because researchers recognized that not all parents may feel comfortable talking about their school within the school where school staff are not far. For some parents, depending on 
individual lived experiences, relationships with the school and/or existing power dynamics with school staff, the school building itself may not be a welcoming space to comfortably share about their school experiences. For these reasons, parents were offered the option to attend focus groups in community locations that, for some, might have been more comfortable. Parents were recruited using flyers distributed in the school and through several community organizations. The hope was that this broad recruitment would invite families who are engaged with their children's schools in various ways and varying degrees. While the focus groups were all conducted in English, in some instances parents supported one another in translation as needed.

In 2019, sampling was more purposeful. The research team wanted to hear from parents who were more actively and physically engaged in the school (e.g., participants on parent advisory committees or volunteers in the school). Recruitment was carried out in partnership with the TDSB, through primarily reaching out to the school's parent council for recruitment support. While translators were offered through the TDSB in 2019, no participants requested translators. Two school-based parent focus groups were held with five parents at MS1 and seven parents at MS2 in 2019.

\section{School Administrators}

Semi-structured interviews were held with school administrators (principals and viceprincipals, hereafter referred to as administrators) at MS1 and MS2 in 2014 and 2019. At MS1 in 2014 two MS1 administrators were interviewed together in one joint interview, as per the school's preference. One of those MS1 administrators was interviewed again five years later, in 2019. At MS2 in 2014, two MS2 administrators were interviewed together in one interview. In 2018, due to staff turnover, two new MS2 administrators were interviewed together in one interview and a follow-up interview was conducted with one of these administrators in 2019. 
For the purposes of this paper, the interview is referred to as taking place at the 2019 time point. In some instances, administrators preferred that the interviews took place with both principal and vice-principal at the school interviewed together. Administrator interviews took place in administrator offices, coffee shops, and one follow-up interview was completed over the phone.

\section{Case Study Sites}

MS1 and MS2 are Model Schools for Inner Cities elementary schools (offering Kindergarten to grade eight classes) located in Toronto and were among the highest ranking schools (top 22 of 473) on the Learning Opportunities Index (LOI) in 2014 and 2019 (TDSB, 2020). The higher the school is ranked on the LOI, the greater the socio-demographic challenges. The TDSB's LOI ranks schools based on a variety of social and economic factors to help measure the "external challenges affecting student success" (TDSB, 2020 p. 2). Schools are ranked on the LOI based on socio-demographic variables such as median family income, adult education levels, and number of families receiving social assistance, among other variables.

\section{Model School 1}

MS1 is located in a downtown, high density neighbourhood in Toronto. The school is within walking distance to the majority of students' homes and nearby to several community services and resources. At the time of the focus groups and interviews in both 2014 and 2019 the surrounding neighbourhood was undergoing a neighbourhood redevelopment and mixed-income housing initiative where social housing buildings were being torn down and replaced by new town houses and condominiums that included a mix of public housing and new private sector housing. Some of these neighbourhood changes allowed for additional community services and new spaces for existing organizations that served the community. 
MS1 recently completed an upgrade to its school built environment and has an on-site childcare centre that had toddler and preschool day programs as well as an afterschool program for kindergarten students (students ages four to five), an EarlyON Child and Family Centre (a provincially-funded centre that offers programming and resources for families, including a dropin program for young children and their caregivers), an on-site school-based paediatric health clinic offered in partnership with a local hospital that opened in 2015, and an adjoining community centre.

The student population of MS1 is linguistically and culturally diverse. According to demographic data collected with standardized tests at MS1 in 2019 with grade three and grade six students, $60 \%$ of grade three students' and $63 \%$ of grade six students' first language learned at home was a language other than English. Demographic data from 2019 also showed that in $16 \%$ of grade 3 students and $11 \%$ of grade 6 students were born outside of Canada.

\section{Model School 2}

MS2 is located in a more sprawling, less dense neighbourhood in Toronto in comparison to MS1. Although the school is in walking distance for many students attending the school, other community services such as community centres, libraries and childcare centres are not generally in walking distance from families' homes. There are notably less community programs and services and in the MS2 surrounding neighbourhood than at MS1. The school built environment at MS2 is deteriorating, with more cramped spaces than at MS1.

The student population of MS2 is also linguistically and culturally diverse. For example, according to demographic data collected with standardized tests collected at MS2 in 2019 with grade three and grade six students, $32 \%$ of grade three students' and $32 \%$ of grade six students' first language learned at home was a language other than English. Demographic data from 2019 
also showed that in $9 \%$ of grade 3 students and $23 \%$ of grade 6 students were born outside of Canada.

\section{Data Analysis}

The present study employs two types of qualitative analyses: (1) phase one involves a descriptive qualitative analysis, and (2) phase two involves explanatory analysis. In the first phase of this study, I conducted a thematic analysis informed by a grounded theory approach (Urquhart, 2013) of administrator interview and parent focus group data. In the second analysis phase, I conducted an explanatory analysis of administrator interview and parent focus data, while considering relevant literature and document reviews of TDSB administrative reports.

\section{Phase 1: Descriptive Analysis}

The descriptive analysis phase of this study involved a thematic analysis informed by a grounded theory approach. Grounded theory, originally conceptualized by Glaser and Strauss (1967), aims to build theory informed by the data. In this inductive approach to qualitative data analysis, researchers analyze data without preconceived notions of theory in order to identify themes and theory that emerge directly from the data (Urquhart, 2013). After reviewing initial stages of descriptive analysis (open coding, inter-rater coding discussions by team members, focused coding in NVivo, qualitative chart summaries summarizing each of the nodes) that were completed by Dr. Patel's research team in 2014 and 2019, I identified the focused codes that had data relevant to my research questions (42 codes from 2014 data, 21 codes from 2019 data) and exported them. My review of the data provided an additional opportunity for an inter-rater reliability check, and I was able to make coding adjustments after discussing with Dr. Patel prior to exporting the data and conducting further coding with my research question in mind. I then summarized the relevant data from these exports into seven major themes. 


\section{Phase 2: Explanatory Analysis}

Explanatory multiple case studies are a relatively new, emerging mixed methods approach in qualitative research. My explanatory analysis was informed largely by Yin's (2018) discussion of case study analysis and other publications that have used an explanatory case study method (e.g., Molnar et al., 2016; O'Campo et al., 2018). See Table 4 for a summary of the explanatory analysis process employed in this study.

\section{Table 3}

Explanatory Analysis Process (adapted based on Yin, 2018; O'Campo et al., 2018)

\begin{tabular}{|c|c|}
\hline Analysis stage* & Activities \\
\hline $\begin{array}{l}\text { 'Playing' with the data } \\
\text { (Getting to know your data) }\end{array}$ & $\begin{array}{l}\text { Reviewing transcripts } \\
\text { Writing research memos about emerging themes related to the research } \\
\text { question }\end{array}$ \\
\hline $\begin{array}{l}\text { Becoming familiar with } \\
\text { existing theory }\end{array}$ & $\begin{array}{l}\text { Reviewing previous literature related to the research question to help } \\
\text { inform theory building }\end{array}$ \\
\hline $\begin{array}{l}\text { Developing a case } \\
\text { description } \\
\text { (Grounded theory) }\end{array}$ & Completing descriptive analyses of the data \\
\hline $\begin{array}{l}\text { Developing plausible main } \\
\text { and rival hypotheses } \\
\text { (Theory building) }\end{array}$ & $\begin{array}{l}\text { Creating visuals (e.g., logic models) to begin theorizing causal } \\
\text { sequences } \\
\text { Developing lists of plausible and rival hypotheses } \\
\text { Choosing the most plausible main and rival hypotheses to test }\end{array}$ \\
\hline $\begin{array}{l}\text { Testing and revising } \\
\text { plausible main and rival } \\
\text { hypotheses } \\
\text { (Explanation building) }\end{array}$ & $\begin{array}{l}\text { Reviewing and coding parent and administrator data for evidence of } \\
\text { chosen main and rival hypotheses } \\
\text { Reviewing literature and TDSB administrative reports for evidence of } \\
\text { main and rival hypotheses } \\
\text { Revising main hypotheses and rivals and coding data sources again }\end{array}$ \\
\hline Rating the evidence quality & $\begin{array}{l}\text { Organizing data sources by the main or rival hypotheses they support } \\
\text { and identifying which hypotheses have thick evidence (robust support } \\
\text { from data sources for the hypothesis), thin evidence (some support from } \\
\text { data sources for the hypothesis), and no evidence (no support from data } \\
\text { sources for the hypothesis) }\end{array}$ \\
\hline
\end{tabular}

\footnotetext{
*Note: These analysis stages are not necessarily sequential
} 
I used a combination of several strategies suggested by Yin (2018) throughout my explanatory analysis process. Yin's (2018) first step in analyzing case study data calls for the researcher to get to know the data. In this stage, I spent time reacquainting myself with the focus group and interview transcripts and revisiting MSIC initiative reports to familiarize myself with the context of the case study sites and to begin brainstorming potential directions of the explanatory analysis. After determining a general focus of school leadership vision and familyschool-community partnerships, I turned to reviewing existing literature to find what theories had emerged in previous research and writing on these topics. A review of existing literature and theory on a given research topic can help to inform the theoretical propositions and future directions of analysis (Yin, 2018). While reviewing existing theory, I also began descriptive analysis of the data, which helped me to (1) develop a case description of each school, and (2) begin to identify theories emerging from the data.

Informed both from my descriptive (grounded theory) analyses of the parent and administrator data and review of relevant literature, I then began to develop and examine plausible hypotheses. During this stage of theory building, and as suggested by Yin (2018), I used visuals (e.g., logic models portraying cause-effect patterns) to help depict the causal sequences I was theorizing. I developed plausible hypothesis statements based on my descriptive analysis and existing theory from literature. For each plausible hypothesis, there were several rival hypotheses that offered alternative explanations of the theory. After creating a list of plausible hypotheses, I chose three main hypotheses that I thought were the most plausible based on my descriptive analysis of the data and the existing literature. Yin (2018) reminds us that researchers should not focus on analyzing the data for all hypotheses and their rivals, but rather focus on the most plausible hypotheses. 
Finally, I began what Yin (2018) calls explanation building. In explanation building "the goal is to analyze your case study data by building an explanation about the case" (p. 179). The explanation building process involved reviewing parent and administrator data in search of evidence that either confirmed or refuted my main plausible hypothesis and associated rival hypotheses. This analysis process, Yin (2018) notes, is an iterative one, where hypotheses will be continuously revised as researchers analyze the data until the hypothesis "works" for most of the sites and data sources. Inspired by the multiple explanatory case study research by O'Campo et al. (2018), I then rated the quality of evidence of each main hypothesis and rival hypothesis. Pairing evidence from the administrator and parent data with evidence from existing literature revealed certain hypotheses that had either 'thick' evidence, 'thin' evidence, or 'no' evidence. O'Campo et al. (2018) note that this process also offers an opportunity for triangulation, where the evidence supporting a particular hypothesis is available from more than one data source.

\section{Validity, Reliability, and Generalizability}

Creswell and Miller (2000) define validity as how credible the research process and analysis is and how true the findings of such research are to the participants' realities. In weekly peer debriefing sessions Dr. Patel and I met to discuss both the descriptive and explanatory analysis and findings, which offered an opportunity to review the research procedures with someone who was acquainted with the research context and social phenomena in order to ensure that my research procedures were appropriate and credible (Creswell \& Miller, 2000). I was able to triangulate findings, a method where findings are supported by more than one data source (Cohen, et al., 2017), in explanatory analyses where administrator and parent transcripts, TDSB administrative reports, and existing literature informed my results. 
Another strength of this secondary analysis was the opportunity for inter-rater reliability. While I was not working alongside other coders, I reviewed the descriptive analysis completed by previous researchers providing an opportunity for an inter-rater reliability check. There were a few instances where coding had to be altered. When this arose, I discussed these changes with Dr. Patel and made the needed adjustments.

Generalizability is thought to be limited in case study research because of the temporal, geographic, and social context-specific conditions of the phenomena (Yin, 2009). However, Yin (2009) suggests that analytic generalizability is possible in case study research, meaning that the analysis of specific case studies can be replicated when proper documentation of the research processes and analyses are kept. Throughout my research process, I kept detailed notes and memos on my analysis procedures. This transparency in the research process ensures that my analysis can be checked, reviewed, and if needed, carried out again to replicate findings. 


\section{CHAPTER 3}

\section{Results and Discussion: Descriptive Analysis}

The following chapter reports on the findings of the descriptive analyses of the 2014 and 2019 parent focus groups and administrator interviews. The research question guiding this descriptive analysis was: Within the context of the MSIC initiative in Toronto, what leadership strategies and practices do school administrators use to foster school-family-community partnerships? The seven themes that emerged in this analysis included: (1) creating a welcoming physical and social school environment, (2) fostering a culture of care, (3) communication with families, (4) encouraging parent leadership and advocacy, (5) leadership presence in the community, (6) establishing the school as a social and cultural brokerage, and (7) leveraging community partnerships and administrators' personal social capital to address systemic inequities. This descriptive results section reports on similarities and differences between the two school sites, with the 2014 and 2019 data treated as one sample in cases where there were no noteworthy differences in findings over time. Where relevant, differences across sites over time were noted and clarified.

Before describing the findings, I offer a note about terminology. In this section and the sections that follow the term 'nondominant' parents/families is used. Ishimaru (2020) uses the term nondominant parents/families to refer to "those impacted by systemic oppression, such as marginalization based on race, class, language, or immigration status, and is a term that explicitly references relationships to dominant power" (p. 8). Ishimaru (2020) notes that this is "an imperfect descriptor" (p. 9) of the experiences of parents and families, and I agree. This term can be critiqued as inscribed with a deficit perspective of nondominant groups, focusing on what diverse groups of people do not have rather than what they do have (Ishimaru, 2020). However, 
this language aims to call attention to the varied ways families experience oppression due to power relations rooted in racism, sexism, ableism, and classism (Ishimaru, 2020).

\section{(1) Creating a Welcoming Physical and Social School Environment}

Parents and administrators described the ways that a welcoming physical and social school environment played a role in how welcomed and invited parents felt in the school. Parents at both MS1 and MS2 spoke about the importance of a welcoming entrance way. At MS1, administrators said that having an inviting entrance helped families to feel welcomed in the school building. One MS1 administrator said:

I think first and foremost it's about ensuring the school is a welcoming space right so though all of the exterior doors are on automatic locks and we have that system that's throughout all public schools. We encourage more free access into the school than maybe other schools. You know parents are coming and dropping their kids off in the morning. I am not berating them for bringing their child into the school. (MS1 administrator, 2019)

Although all schools in the TDSB have automatic locks on their doors, administrators strived to allow for more free access for families into the school. Conversely, the front entrance at MS2 was described as small and not welcoming by both parents and administrators. There were a few stairs just inside the front entrance of the school, making it inaccessible for people using wheelchairs/walkers or parents with strollers. In 2014, one M2 parent said, "How do you have a parenting [centre] here and no ramp? Does that make sense? Do the connection here. At least make one side a ramp and the other side stairs." The inaccessible entrance was a barrier for parents accessing the EarlyON Parent and Child Centre in the school.

Both MS1 and MS2 parents also discussed the important role of all school staff, not only teachers and administrators, in establishing a welcoming environment. Administrators too discussed how having approachable staff, especially front desk staff, was crucial to having parents feel invited in the school space. However, although most parents at MS1 and MS2 said 
school staff were generally welcoming and friendly, some parents at both schools did not feel as welcomed or cared for by front desk staff. MS1 parents spoke often about how they felt comfortable approaching the administrative team at their school with any issue. MS2 parents spoke highly of a now retired school custodian who knew families by name and was described as friendly, approachable, and involved with the school. One MS1 parent explained that the way that parents are first welcomed by school staff is reflective of the broader relationship between the school and community.

Parents' and administrators' comments reveal that establishing a welcoming atmosphere at the front entrance, both physically and socially, as well as ensuring school staff are approachable and know parents by name are key administrative strategies to ensuring families feel invited in the school. Indeed, previous research has highlighted that a welcoming, "homelike", school atmosphere can transform how parents perceive school climate and make families feel more comfortable and at ease in the school environment (Ishimaru et al., 2016, p. 867). Similar to the finding presented here where MS2 parents felt known by the custodian, FitzGerald and Quiñones' (2019) study of school leadership at a community school in the USA found that when parents felt seen and known by school staff they felt welcomed and included in the school environment.

Researchers have also highlighted the important role that school leaders play in establishing a welcoming and inviting tone in the school (Barr \& Saltmarch, 2014; Valli et al., 2016). In the present study, the principal at MS1 was intentional about creating a welcoming front entrance, while parents at MS2 noticed how the lack of accessibility at their school may have created a barrier to parents even entering the school. Auerbach (2010) notes that creating a welcoming school environment is one of the more traditional strategies to encouraging family 
and community engagement. MS1 and MS2 administrators' intentional efforts to create a comfortable physical and social environment for families may make parents feel more invited in the space, but as Auerbach (2010) notes, this alone will not likely lead to deeper, more collaborative partnerships between families and schools. In addition to a welcoming social and physical environment, fostering caring and trusting relationships between school staff and families is required for partnerships to flourish.

\section{(2) Fostering a Culture of Care}

Administrators at both MS1 and MS2 identified fostering a caring school culture as an important strategy to ensure families felt comfortable being involved in the school. Administrators' vision of a culture of care, though, differed. MS1 administrators' vision was broad and included a focus on caring about families' well-being, student educational success, the larger community, and social justice. MS2 administrators' vision of a culture of care focused more on fostering caring and loving school staff-family relationships built on relational trust.

MS1 administrators' strategies to foster a culture of care included ensuring that the vision of a culture of care was visible in the school building and mentioned often in conversations with students and families. The culture of care vision was posted in the entranceway, referred to in newsletters sent home to parents, and spoken about in school announcements. Near the school office, a board was displayed, where students were acknowledged when they were seen caring for another student or caring about their academics. MS1 administrators said that these strategies helped to ensure that the vision of a culture of care was embedded in the interactions between staff, families, and students. MS1 parents explicitly mentioned this culture of care in focus groups and indeed felt that the school cared about students, families, and the larger community. For example, while talking about community partnerships one MS1 parent said: 
We are building a community of caring and showing that the school and the neighbourhood are one. It's not like separate entities and just being that neutral place for everyone in the community to be able to feel welcomed and comfortable and that's something I feel very strongly here. (MS1 parent, 2014)

MS1 parents felt as though they contributed to creating this culture of care in the school. This parent highlights a sentiment that was mentioned by many, that this culture of care meant parents felt more welcomed and comfortable being involved in the school. For MS1 parents, a culture of care also involved the school respecting and valuing racial, cultural, and religious diversity and being actively engaged in anti-racism and anti-discrimination. Indeed, MS1 administrators spoke often about their anti-racist, anti-oppressive stance and said they did not tolerate racism and discrimination in their school. Parents appreciated that MS1 school staff and administrators promoted student and family pride in their cultures and religions.

MS2 administrators' strategies to foster a culture of care focused more on building trusting and caring relationships between school staff and families. Both 2014 and 2019 MS2 administrators recognized a sense of distrust between parents and school staff and attributed this this distrust to parents' past traumas or negative experiences with schools. MS2 parents in 2014 corroborated this and spoke about how they did not trust school staff. For some MS2 parents, their feelings of distrust were related to power dynamics. One MS2 parent in 2014 said, "I don't really feel comfortable. I have seen it happen too many times. Teachers and everybody at the school have too much authority in the sense that if they don't like me, they can make my life hell." This MS2 parent's distrust was related to feeling that school staff would abuse their power if school staff and parents did not get along. Other parents were distrustful due to a lack of communication between the school and their family where parents felt they rarely got the "whole story' from staff about incidents involving their children. There seemed to be more trust between 
MS2 parents and school staff in 2019, where MS2 parents reported that school staff were very transparent in their communications with parents.

In 2019 MS2 administrators spoke more explicitly about strategies to build trust with parents than MS2 administrators did in 2014. MS2 administrators in 2019 noted that their first year at the school was focused on building caring and trusting relationships with parents. One MS2 administrator said:

It was all building relationships last year with all stakeholders. Not just our students but the families, the parents, the caregivers, the staff, everybody, right? So I think this [the office] is a safe place for them which is why they [students] come down here a lot. They know that [when] they come they'll get a hug whatever they need. Get a meal, get attention. (MS2 administrator, 2019)

One way that MS2 administrators built trust in 2019 was by establishing the school office as a safe, caring space where students could access support when needed. MS2 administrators also noted, though, that this process of building trust takes time. In 2019 one MS2 administrator said:

Building trust is an individual thing... it is literally child by child, parent by parent, family by family... because they are marginalized already so they need proof in the pudding right? And then if something happens [and that trust breaks], then we have to build that all over again. (MS2 administrator, 2019)

This MS2 administrator highlighted that building trusting relationships happens one-on-one with each individual family. MS2 administrators also noted that hiring is key in developing a trusting and caring school culture because students and families can tell whether or not staff truly care about their well-being. MS2 parents in 2014 corroborated this. One MS2 parent said, "There are certain teachers that really do care and there are certain teachers who are just there to pass through because they want their pay cheque." MS2 parents recognized and appreciated the staff who deeply cared about families' well-being.

These findings highlight a few different ways that administrators can foster a culture of care in order to encourage future parent engagement. MS1 administrators'strategies to foster 
their broad view of a culture of care included creating an inclusive school environment where nondominant parents felt respected and cared for as well as encouraging parent and school-staff to buy-in to the vision of a culture of care by embedding the vision in communications with families and displaying the vision in the school building. This finding is similar to DeMatthew's et al. (2016) study about a social justice leader in an elementary school in Mexico. DeMatthew et al. (2016) found that central to the leader's social justice work was creating a school environment that demonstrated care for students beyond their academic achievement, where the school also cared about and cared for students' families and larger community. In the present study, the MS1 administrators' commitment to social justice, anti-oppression, and anti-racism created a culture of care where parents recognized and bought into a shared sense of care and respect for the school, families, and community. MS2 administrators' core strategy to establishing a culture of care centred on developing caring and trusting relationships between school staff and families. In line with previous research, administrators (at MS2), particularly in 2019, played key roles in establishing caring and trusting relationships with families (e.g., FitzGerald \& Quiñones, 2018; Khalifa, 2012) and building that trust was key in laying the groundwork for future functioning of the school-family-community partnership (Barr \& Saltmarsh, 2014; Bryk \& Schneider, 2002).

\section{(3) Communication with Families}

Administrators and parents discussed both informal (e.g., casual conversations) and formal (e.g., parent council) communication strategies employed by the schools through which parents, school staff, and administrators connected. At both schools, communication seemed to improve between 2014 and 2019. Parents valued administrators and school staff who made them feel heard; those school staff who took time to listen and meet with parents and quickly address their concerns. 
In both 2014 and 2019, MS1 administrators spoke of several strategies they used to communicate with families, including through weekly newsletters, phone calls, and social media. MS1 parents' perspectives on communication with the school seemed to improve between 2014 and 2019. Most MS1 parents spoke positively about school-family communications in 2014, but a few parents said that the school never called to tell them about school events and that they did not receive flyers about events. In 2019 parents' perspectives on communication seemed to improve, where all MS1 parents spoke positively about family-school communications, saying parents "can't miss" anything happening in the school (MS1 parent, 2019).

In 2014 many MS2 parents felt there were limited opportunities or avenues to raise concerns with administration. Parents noted a lack of communication and organization between school staff, where, for example, parents received calls from school staff who said their child was not at school, and then later would receive a call saying the child was indeed at school. There seemed to be a shift in 2019 at MS2 where communication with administrators and the school improved. Parents noticed that they felt more comfortable approaching administrators with their concerns than they had in the past. In 2019, MS2 parents and administrators spoke about several ways that the school communicates with families through flyers, emails, phone calls, informal conversations, and events, such as a parent event organized by administrators and the MSIC Community Support Worker where parents can chat with school staff over tea. The MSIC Community Support Worker seemed to be a key communication link for parents. One MS2 parent in 2019 said, "[The MSIC Community Support Worker] is at your beck and call. Whenever you need her you can call the school or you can get in contact with her, she is always around." 
Administrators at both MS1 and MS2 said it was important for parents to feel validated and heard when a concern was brought to their attention so they could work together to solve the issue. The parent council was an important avenue at MS1 through which parents can feel confident that their concerns are being heard by administrators. Although MS2 administrators recognized that parents value when their voices are heard, MS2 administrators in 2014 did not speak explicitly about ways that parents can raise their concerns, except for saying that school staff accommodate parents' work schedules and will talk with parents over the phone as needed.

Parents at both MS1 and MS2 discussed the importance of receiving phone calls about when their children are doing well in school, not only when their children are struggling. At MS1, they appreciated phone calls about their children's good behaviours and achievements and felt these phone calls contributed to a sense of pride in their parenting. One MS1 parent spoke about how administrators collaboratively worked with families when there is a concern with their child and. An MS1 parent said:

[The administrators] don't jump the gun and say oh we are going to call so and so because your kids a bad influence on these other kids, because you are a bad parent. They actually talk to you and help you out. (MS1 parent, 2014)

MS1 parents especially appreciated that school staff did not blame the parent when an incident happened with their child. At MS2 in 2014, parents desired more phone calls like this. For example one MS2 parent said, "Why do I always have to get the negative phone call? All you are going to do is call me and tell me negativity. You're never going to uplift my child. You're always going to put down my child.” This MS2 parent expressed frustration about receiving phone calls only about her child's negative behaviour and desired calls celebrating his achievements as well to help uplift her child. 
Overall, parents appreciated frequent and varied opportunities to connect with school staff. Communication between the school and parents seemed to improve between 2014 and 2019. While the sampling strategy was purposive at MS1 and MS2 in 2019 to include families who were actively involved with the school, there was converging evidence of improvements in communication between 2014 and 2019 with families found in both the administrator interviews and the parent focus groups. Feeling validated and heard in conversations with administrators and school staff was important for parents, as was having conversations about their child's successes in school, not only their challenges. Creating various opportunities for parents to share their input about what they want communicated with them is important (Patel et al., 2008). These findings reflect research on school-family-community partnerships that has found that consistent, frequent, and varied two-way avenues for communication, through which families and community can reach out to the school and the school can reach out to families and communities, play an important role in fostering partnerships, particularly for nondominant families (e.g., Epstein, 1995; López et al., 2001; Medina et al., 2019; Patel et al, 2008; Patel \& Corter, 2013). Interacting with parents on a regular basis has been found to be related with family-school relations, where frequent in-person communications plays a role in fostering relational bonds between parents and school staff (López et al., 2001). Previous research has also pointed to the possibility that having multiple avenues of communication at the school leads to more invitations to be involved in the school, which could have implications for future school engagement (Patel \& Corter, 2013).

\section{(4) Encouraging Parent Leadership and Advocacy}

Administrators who spoke explicitly about strategies they used to encourage parent advocacy and leadership had active parent councils that took a leadership role in school and 
community initiatives. MS1 administrators spoke explicitly about such strategies. In 2014 at MS1, parents and administrators reported that the parent council had recently began doing work beyond only supporting the school, but also supporting local community charities. The parent council at MS1 led advocacy efforts to have more spaces in local recreation programs for community residents, to get school uniforms, and led parent events in collaboration with the MSIC Community Support Worker, an event where an invited speaker would discuss topics chosen by parents. In 2019, MS1 parents were actively involved in recruiting and encouraging more parents to join the parent council. The MSIC Community Support Workers and school administrators were described by parents as co-leaders in the parent council. One MS1 parent spoke about how the parent council is a space where parents can grow into advocates who use their voice to create change. MS1 administrators described some ways parents took leadership roles in the school. One MS1 administrator said:

The staff see that the parents are actively involved in fundraising and [that] they're the ones actually taking the leadership role in implementing the new uniform policy. I think it makes them [staff] even more aware yes these parents have the ability to give back... it's just for us to kind of guide them to get there. (MS1 administrator, 2014)

MS1 administrators encouraged staff to view parents as important leaders in school and community partnerships. Administrators at MS2 in 2014 did not speak about specific strategies to encourage parent leadership. The parent council was not as active at MS2 in comparison to MS1 at both time points. MS2 administrators noted that MS2 parent engagement in the parent council fluctuated over time, and that their main role was to organize hot lunches for students. Parents at MS2 were not taking on a leadership role in terms of school or community initiatives in the way that parents were at MS1.

In line with previous research, MS1 efforts to distribute leadership to parents by creating opportunities for parent leadership in school and community activities seemed to have 
implications for the level of parent engagement in their parent council and school generally. Notably, there seemed to be a lack of opportunity for parent leadership at MS2 and less parent engagement in their parent council. The importance of shared leadership in school-familycommunity partnerships through practices such as parent council and parent-led events is well documented (e.g., Adams, 2019, Adams and Jean-Marie, 2011; FitzGerald \& Quiñones, 2019; Krumm \& Curry, 2017; Ishimaru, 2018; Peterson \& Durrant, 2013). These efforts to continually flatten power hierarchies between schools, families, and communities offer the opportunity to coconstruct the school environment. For example, MS1 parents' leadership on planning a uniform policy meant that parents acted as key decision-makers in school policy and played a role in the co-construction the school. Researchers have suggested that such activities may contribute to families' feelings of ownership and belonging in the school (Quiñones \& FitzGerald, 2019; Ishimaru, 2013). Additional research is needed to discover possible causal links between shared leadership models, families' feelings of ownership and belonging, and family and family engagement.

\section{(5) Leadership Presence in the Community}

Parents at MS1 and MS2 appreciated when school staff were visible and present in their community. For example, MS1 parents spoke about how their MSIC Community Support Worker was a basketball coach in the neighbourhood, which made parents feel that the school was an active, supportive member of the larger community. Administrators at MS1 were involved in and attended community events and visited local community centres and organizations. The neighbourhood was undergoing a revitalization and administrators would attend the community meetings regarding revitalization. One MS1 administrator in 2014 said that: 
... attending community meetings [is something] as a school administrator we should be doing, but I just feel like when we go to those community meetings it should be more in a support capacity with our families, not that we are getting the information [about the redevelopment] there too. (MS1 administrator, 2014)

MS1 administrators attended these update meetings to support and act as co-advocates with families. At MS2, there was only mention of the school staff presence in the community in 2019. MS2 administrators reported taking school staff on community walks led by community representatives so that the staff could get to know the community and get a sense of what families lives were like outside of school hours. For example, one MS2 administrator said:

Last October we went on a community walk and it was the first one that they ever did and we actually had members of our community lead that walk... We went to the buildings right next door. We went to the Food Bank, the clothing bank, the community garden. The representatives from the community were really specific about not looking at it from a deficit model so the strengths and the richness of the community. And I believe the staff got a lot of that. (MS2 administrator, 2019)

Although community walks were a regular and common practice in many schools in the MSIC initiative, administrators noted that school staff at MS2 had never taken part in one until recently. MS2 administrators said that after the community walk teachers had a better understanding of what types of supports were available to families and some teachers planned field trips to visit local community organizations with their class.

In 2019, MS2 administrators and school staff hosted an intergenerational reading club and parent council meetings in the community rooms of one of the local apartment buildings. After noticing low parent council attendance numbers, MS2 administrators began holding some meetings at the apartment buildings because they recognized it was difficult for some parents to get to the school in the evening. Two parents spoke about how they appreciated that the school held meetings and events in the community. One MS2 parent said:

We're meeting at 6:00 p.m. in the Community Housing Room. Okay, this a place where someone was just killed a couple of months ago. It's not the safest place to be if you 
wanna just look at the stats and these Principals and Vice Principals and teachers are coming there 6:00 p.m. This is hours after they've finished, they're not being paid to be there and they're sitting with the community for one reason, to get feedback from the community on what we can do to better enable the students and the teachers at our school to help us to learn and to grow as a community. (MS2 parent, 2019)

School staff presence in the community demonstrated to families that staff were willing to go the extra mile to connect with parents. Administrators' and school staff's presence in the community demonstrated to parents that school staff felt that they were a part of the larger community. Similarly, Khalifa's (2012) study of one principal's practices in fostering school-familycommunity partnerships found that the principal's presence in the community through frequent home-visits established the principal as what Khalifa (2012) calls a community leader. Families and community members described the principals in Khalifa's (2012) study as a friend and supporter who they could turn to share community or personal concerns. Parents at MS1 felt the administrators' and MSIC Community Support Workers' presence in the community through community meetings and recreational activities demonstrated that they cared deeply for families and the community. Consistent with findings at MS2, hosting school meetings in community locations has also been found to be an important strategy in fostering family engagement (Ishimaru, 2018). Still, the findings of this study, and others (e.g., Green, 2015; Khalifa, 2012), demonstrate the potential and importance of school leaders not only being present in the community in the physical sense, like at MS2, but also in a co-advocacy sense, like at MS1.

\section{(6) Establishing the School as a Social and Cultural Broker}

Administrators at both MS1 and MS2 established their schools as a social and cultural broker for families by acting as a resource to assist families and communities in decoding, navigating, and accessing dominant cultures and social systems thereby increasing families' social and cultural capital (Green, 2018; Lopez \& Stack, 2001), although in varying degrees. 
MS1 parents and administrators spoke often of the ways their school acted as a social broker and spoke highly of the co-located service model the school redesign afforded. MS2 had less on-site spaces for community services, but referenced key staff members who acted as links between families and local supports and resources in 2019.

Schools acted as a social brokerage for families by offering either on-site services or referrals to services that supported families' health and social well-being. In 2014 and 2019, MS1 parents and administrators described numerous on-site programs and services for children and families, including an on-site school health clinic, a parent and child family support program, childcare centre, and extra-curricular before and after school programs offered by community groups in the school, along with an adjacent community centre. One administrator noted that the school was open and active from 7 am to $7 \mathrm{pm}, 7$ days a week. In 2014, in speaking about onsite services, MS1 administrators noted that:

[The school] truly becomes the hub of the community and I think people enjoy the fact that the school is a place that's 7 til 7 and there is a rich variety of things that they can do and access 7 days a week in this space. (MS1 administrator, 2014)

Having activities at the school outside of traditional school hours contributed to the establishment of MS1 as a community hub.

Both MS1 parents and administrators said that the school clinic was particularly helpful and important for families as a place where children and families could quickly receive care, health screenings (e.g., vision, dental) and referrals to other healthcare services. Administrators spoke about how having an on-site clinic was important for families who at times would not follow-through with referrals, either due to the distance or stigma of accessing traditional hospital and mental health clinic spaces. One MS1 parent spoke about how having the clinic 
provides a one-stop model for families, reducing the stress of navigating a fragmented healthcare system.

Although there were less on-site programs and services available at MS2 than at MS1, MS2 parents in 2019 spoke about the school as a place they could turn to for referrals and support. One MS2 parent compared MS2 to a previous school that their daughter attended saying that they felt "isolated" from support at the previous school. The same parent said:

If I was in a situation [where I needed support], the first people I would go to is the Principal, Vice Principal, community workers right here [at MS2]. I wouldn't even have to talk to my family, I would come right here and I would talk to these people and I would get my needs met. Hundred percent. Or they would refer me to somebody who can. There are resources here that can keep any female or any mother, any father, single fathers are here as well, afloat... My point is we're afloat and they [the school] stabilize us. The programs that we're having I'm hoping never get cut because they're very necessary for the generations to come. (MS2 parent, 2019)

This parent views MS2 as a key resource for social support and felt comfortable to go to the school staff before talking to their own family. In 2014, one MS2 parent reported how the school helped to provide glasses and hearing aids for her children who were hard of hearing and vision impaired.

MS1 and MS2 acted as a cultural broker in that families, particularly newcomer families, could find support to navigate Canadian health, education, and social systems at the school. Administrators and parents at both MS1 and MS2 reported that the MSIC Community Support Worker was particularly important in supporting the vision of the school as a cultural brokerage. In 2019 at MS2, the MSIC Community Support Worker was often mentioned by families and administrators as a key support for families as they navigated social, education, and health services. MSIC Community Support Workers, along with on-site TDSB Settlement Workers, were described by MS1 and MS2 parents as particularly important for newcomer and refugee families. MSIC Community Support Workers and TDSB Settlement Workers helped families to 
connect to settlement services, local transportation, and childcare. Still, one MS2 parent and one MS1 parent spoke about how the school could be more supportive of newcomer families. One MS2 parent said:

I think what they need to do when a new person comes into the country and you know this is a new family give them a little pamphlet in their language. Explain the school system in Canada.... So let them know what is okay and what is not okay. And then I think they will feel more comfortable even if there is a language barrier. You can say okay I want to talk to you, it's okay, come at this time, we are going to have a translator to speak with you and then you go and feel more comfortable coming to the programs that we have. (MS2 parent, 2019)

This parent's comment highlights the importance of providing newcomer families support in navigating the school system so that families feel more comfortable in the school community.

There was a noteworthy difference between MS1 and MS2 vision of the school as a site of social and cultural brokering in 2014. For example, one MS2 administrator in 2014 said:

The role of the school I think in every school has changed. Right, like society has changed in just over four years... I see more and more permits, so they [outside agencies] are looking at schools to offer more and more programs for kids so that has changed... And I think also at the same time full day kindergarten has had a big impact at what schools are looking like because now parents are looking at their young ones coming to school for the full day. They are no longer looking at daycare. So I think that has also changed because they need something to bridge from 4 to 6 or 8 until school starts. (MS2 administrator, 2014)

MS2 administrators in 2014 attributed the drive for the school to act as a social or cultural brokerage came from community organizations wanting to partner with the school and the advent of Full-Day Kindergarten (in 2010 Ontario shifted half-day kindergarten for 4 and 5 year olds, to a full-day model). In contrast, MS1 administrators' vision of the school as a social and cultural brokerage was rooted in their personal historic understanding of the purpose of schools. For example, one MS1 administrator said:

Back in the 70's, early 80's this school and school's similar, when I was a student, you had a full time nurse. We had dental care. We had you know, breakfast and lunch programs. So all these pieces and then you know a certain era came and they were 
removed and so now it's sort of putting those pieces back... I don't think... there is greater emphasis now, but if you don't have that historical lens then it seems, "oh this is more." But for me it's just doing what was always done and I think in many ways what should be done in all schools right. There needs to be an opportunity for people to engage in the space beyond the instructional time. (MS1 administrator, 2014)

This MS1 administrator's vision of the school as a social and cultural broker was also grounded in this particular administrator's experience as a student. School administrator vision and personal experience with school may play a role in the degree to which they 'buy-in' to the MSIC initiative's vision of the school as a community hub and therefore the degree to which schools act as a social/cultural brokerage for families.

In line with previous research (Khalifa, 2012; Muijs, 2007), the present study suggests that leaders' vision of school-community overlap and attitude towards partnerships may influence school-family-community partnerships. Leaders who envision the school as a place that can and should welcome community members and organizations into the school work to position the school as a community asset and establish the school as a social broker for families (Green, 2015; Green 2018). In addition to social brokering, the present study found that schools in the MSIC initiative can be sites for cultural brokering as well. Contributing to research that highlights the important leadership role of family and community liaisons in family engagement and cultural brokering (FitzGerald \& Quiñones, 2018; Ishimaru et al., 2016; Yohani, 2011), the present study similarly found the MSIC Community Support Worker and the on-site TDSB Settlement Worker to be key leaders in cultural brokering.

\section{(7) Leveraging Community Partnerships and Administrators' Personal Social Capital to}

\section{Address Systemic Inequities}

There was evidence at both MS1 and MS2 that administrators leveraged community partnerships and their own social capital to address systemic inequities, which parents noticed 
and appreciated. This was more pronounced at MS1 than at MS2, although there was a slight shift towards more school-based efforts to address systemic inequities at MS2 in 2019. Systemic inequity in the present study encompasses a broad range of both structural and systemic conditions that can cause inequity. Systemic inequity occurs when social groups (based on socioeconomic status, ethnicity, race, gender, culture, and/or ability) are disadvantaged compared with other groups in result of historic and cultural socio-economic conditions and structures that systematically privilege specific social groups over others (Dani \& de Haan, 2008).

\section{Partnerships to Address Systemic Racism}

Administrators at MS1 described several ways that they had leveraged community partnerships with universities, not-for-profit organizations, and hospitals to address systemic racism. For example, administrators at MS1 partnered with community agencies to offer coding clubs led by women who were visible minorities targeted at engaging girls to explore fields typically dominated by men. MS1 administrators also recognized that Black boys in their school were interested in video games, but Black men were not adequately represented in the field of technology and creating video games. Administrators partnered with another community organization to offer a coding club targeted specifically at Black boys. In a partnership with a local university, MS1 delivered professional development courses for MS1 school staff and staff from other schools in the local neighbourhood on Afri-centric math pedagogy after administrators reviewed research tied to the school's standardized math test scores. Additionally, the school partnered with health care and mental health organizations to offer child and parent programs focused on behaviour management and relationship building skills. MS1 administrators hoped that these programs would help to address the suspension rates of racialized 
students in a manner that was "supportive as opposed to punitive." For example, one MS1 administrator said:

When you talk about some of those pieces that make the parents feel comfortable in this school, [this child and parent program is one way]. Because again, we are not approaching whatever is happening with their child in a deficit kind of model. Saying your child can't do this and this... and throwing labels on the child. It's more about, we feel your child could do better, how could we service you better? Here is one thing that we can do. (MS1 Administrator, 2019)

This MS1 administrator's comments note that beyond being a support for children, these programs also resulted in parents feeling more comfortable in the school, because the programs worked from a strengths-based model. MS2 administrators spoke less often about specific partnerships they developed to address systemic racism. In 2014, there were no mention of partnerships to address systemic racism like the efforts at MS1 to address disproportionately high rates of suspensions for racialized students. In 2019, like MS1, MS2 administrators had begun professional development for staff focused on Black student excellence, anti-bias training, and culturally relevant pedagogy. This professional development series was part of a larger, boardwide initiative targeted at supporting Black student success (TDSB, 2019a). In another example, after having low parent engagement at workshops about literacy, math, and other academic topics, MS2 administrators partnered with a community organization to offer a workshop on the topic of "trauma and racialized views," but again had low parent attendance. Overall, MS2 had less parent engagement in parent workshops than at MS1.

Administrators at MS1 and MS2 also leveraged their own social capital and position of power in the school to ensure the nondominant families in their school were represented in school leadership and school resources. At MS1, administrators ensured their school community's diversity was reflected in both school staff and on parent council. One MS1 administrator in 2019 said: 
[We have] a staff that reflects the diversity of the community... Myself, I think as a southAsian leader for the school, they understand when it comes to dealing with racism I understand what they are going through and I try to put structures in place to mitigate that across the school. (MS1 administrator, 2019)

Having leadership that reflected the diversity of the school helped to ensure that the school continued to work with an anti-oppressive and anti-racism lens and created a sense of allyship with parents. MS1 administrators intentionally recruited parents to ensure parent leadership represented the diverse cultural, racial, religious, and lived experiences of families in the school. At MS2, administrators in 2019 also spoke about a lack of diversity in the books and resources used in classrooms:

I think a big [impact of the MSIC initiative] is finding things that are relevant to our students so having access to budget to look for those things, resources. And it's hard. It's really hard because if you look at our school it's quite diverse but things are normalized. Kids, they don't have books about kids say of East Asian descent that doesn't revolve around them being East Asian. (MS2 administrator, 2019)

The additional funding the MSIC initiative afforded was important for MS2 administrators in 2019 so they could buy more resources that reflected the ethno-racial identities of families in their school.

\section{Systemic Ableism}

MS1 administrators also leveraged their position within the educational system to advocate for greater access to programming for students with disabilities. With additional space in the school afforded by the school redesign, administrators advocated within the school board for their school to offer Autism and developmental delay programs for students from primary through to intermediate grades so that children would no longer have to leave the community to access such programming. MS1 parents said that having these programs at the school was important for creating an inclusive environment for both children and families, where they felt welcomed and a sense of belonging in the school community. 


\section{Food Insecurity}

Both MS1 and MS2 has breakfast and lunch programs for students supported by the MSIC initiative (TDSB, 2016) to address food insecurity in their school communities. In addition to these programs, MS2 parents also mentioned a food sharing program at the school offered in partnership with a community organization. The food security and nutrition programs offered through the school were noted by MS2 administrators and parents as particularly important for MS2 families. Because grocery stores in the community were located far from families' homes, there were often long line ups at the nearby food bank. Parents also spoke about feeling that there was stigma associated with using the food bank, so avoided going.

\section{Access to Extracurricular Activities}

MS2 administrators in 2019 recognized that there were limited nearby community resources, services, and recreation activities in the neighbourhood and so administrators were working towards offering more programs and clubs within the school in partnership with local organizations. For example, one MS2 administrator in 2019 said:

There is a lot of opportunity for our students [here in the school] because they don't get to go to a lot of the other excursions or [extra curriculars], so with the [MSIC] funding they have really benefited from that, like having arts groups in here. (MS2 administrator, 2019)

This MS2 administrator highlights that their school was a place to connect families to social opportunities and experiences that students in the community may not otherwise have access to. MS2 parents in 2014 appreciated that the school helps them to access local attractions through programs like the community passport, a MSIC initiative program which provides families with coupons for city-based attractions, such as art museums and science centres (TDSB, 2016). One MS2 parent in 2019 said that there was always something happening in the school. They said, "We're talking Wellness nights, we're talking Basketball Programs... there's so many things 
that, it's just every week it's going on." There seemed to be less social programming for children and parents in 2014 at MS2. MS2 parents in 2014 desired more extracurricular programming before and after school and an on-site childcare to reduce parent stress around pick up and drop off.

\section{A Desire for More Relevant Parent Programming}

At MS2 in 2019 there appeared to be a disconnect between the types of programs and events the school was offering and the types of programs parents wanted. MS2 parents had a clear desire for the school to address systemic issues such as unemployment, food insecurity, addiction, teen pregnancy, and other issues. They felt the programs offered by the school were "band-aid" solutions that did not address the root of community challenges. One MS2 parent in 2019 said that in order for families to engage in school, parents need to feel that schools are supporting the parents' social capital. They said:

There's people [in the community] who will take the initiative on their own and find the resources out there and get on their feet and get momma to help or sister to help and they can get their kids but there's some of us who don't have that support - how do we ever, ever get out of this stagnation? How? It's only the school or the people you are involved in daily that can help. [They can say] here's an opportunity for you. I don't see that really coming my way. It's an issue... you just can't ever get up. It reflects on the community. It reflects on people who have addiction problems. It reflects on so many issues that we just can't ignore those issues and say okay what's going on here at this school. (MS2 parent, 2019)

This MS2 parent views the school as a place that can help address generational cycles of poverty, addiction, and other social justice concerns, particularly for those families who have no other social networks. This MS2 parent continues to express a desire for the school staff to act as an ally to families. They said:

I love the community workers and what they do here and I know that their heart is real, but I don't know if everybody has an ear to hear. People hear but they don't hear. And I feel like you are really not addressing the core of what needs to happen. If you have a position of authority and you are not going down to your municipal councillor... or... 
your government as a person of authority that represents this community and then

speaking on our behalf, then don't speak to me. (MS2 parent, 2019)

This parent calls on school staff to use their social position to advocate for better community health and well-being.

\section{Administrator Vision}

Administrator social justice vision seemed to play a role in the degree to which their schools actively addressed systemic inequities in their school. Underlying the partnerships and efforts to address systemic inequities at MS1 was an intentional and explicit anti-oppressive stance that MS1 administrators often named in conversations with families, in newsletters, and in parent council meetings. MS1 administrators believed that by naming their anti-oppressive stance with parents they could demonstrate to families that the school cares about issues impacting the lives of students, families, and the community. For example, in regards to outreach efforts to families and communities one administrator at MS1 noted that they:

...think its ongoing work around equity and putting an anti-oppressive stance at the center of the work that we do... When for instance our newcomer black families see the work that we are doing around promoting excellence explicitly for black children and naming it, it makes them realize we care deeply about their children. We see where there are gaps in provision of services for black children across the system and how we are trying to address that at [MS1]. (MS1 administrator, 2019)

By naming the school's anti-oppressive stance, administrators highlight to families that they intend for their school to act as co-advocates with families for more equitable educational and social systems. A few MS1 parents also spoke to the school's social justice stance. For example, one MS1 parent said, "You find leaders [who] just turn the page, they just hide these things [inequities]. But these things will harm a lot. Equity and human rights has to be [a] serious issue." For this parent, it is important that administrators take social justice seriously and do not ignore existing inequities 
Administrators at MS2 did not speak as explicitly about addressing systemic inequities in their school in comparison to administrators at MS1. In 2014, MS2 administrators recognized and named some of the systemic inequities that exist in the community, such as poverty, food insecurity, young pregnancy rates, and a lack of community resources, but did not mention how they work to address these systemic issues in their school, except for noting the school's breakfast and nutrition programs for students. In 2019, there was a shift towards some more intentional efforts to address systemic inequities in the school.

Overall, administrators at both MS1 and MS2 recognized systemic inequities in their communities and to some degree strived to address these systemic inequities in their school, although MS1 seemed to be more intentional in these efforts. MS1 participants shared examples of ways the school was addressing systemic racism, food insecurity, and systemic ableism by leveraging community partnerships and administrator social capital and with support from MSIC initiative funding. MS1 administrators often explicitly voiced their social justice stance in conversations with parents and families. Parents appreciated that equity and social justice were core values of their school. Similar to what was found at MS1, previous research has shown that principals who are committed to enacting social justice and equity and champion community concerns will identify the root cause of inequities and work to address them within the school (DeMatthews et al., 2016; Green, 2015; Theoharis, 2007). The findings in the present study also support previous research that contends that social justice leadership is key in establishing and maintaining school-family-community partnerships that strives to improve student academic achievement and family and community well-being (Hernandez et al., 2014). Although MS2 participants mentioned efforts to address food insecurity and access to recreational opportunities for students, MS2 parents desired more relevant programming to meet their community's needs 
and for school staff to be allies with families and communities in advocating for greater equity. These findings reveal that transparency about the intention of engagement events and activities for parents and ensuring these events are relevant to the lives of families by effectively consulting with families is important to ensure parents in fact engage in these events and trust that administrators and schools are their allies in addressing their community concerns. Indeed, previous research confirms the importance of collaboration with parents and community members to determine and shape the school-based services, resources and programs that are most helpful and relevant for the community (Goldfarb \& Grinberg, 2002; Peterson \& Durrant, 2013). 


\section{Results and Discussion: Explanatory Analysis}

This chapter reports on the results of the explanatory analyses. In this analysis I first generated a list of seven plausible hypotheses (including main and rival hypotheses) informed by the secondary data, TDSB administrative reports, and previous literature. Similar to the analytic approach in the multiple case study method by Molnar et al. (2016), hypotheses were tested by identifying context-mechanism-outcome pathways in the three data sources. Each hypothesis was tested by coding the secondary data and referring to literature and TDSB administrative reports for evidence of context (including program features and moderating circumstances at the relevant case study site[s]), mechanisms of change, and outcomes that supported or refuted the seven plausible hypotheses. Based on this analysis, three of the seven hypotheses were accepted as the most plausible with adequate support from at least two data sources (for example, thick evidence from one case study site and support from literature). This chapter will report on the evidence, including the secondary data and supporting literature, supporting these three accepted hypotheses by discussing the context, mechanisms of change, and outcome operating in each. Three plausible hypotheses aimed to answer the following research question: Within the context of the MSIC initiative in Toronto, how, or through what mechanisms of change, do school leaders with a vision of social justice who collaborate and share leadership responsibilities with families affect family well-being and student educational success? In this study family wellbeing and student educational success are broadly conceptualized. Family well-being refers to a sense of wellness amongst family members and the family as a whole. Family well-being can be influenced by factors such as child and parent health and mental wellness, family social and cultural capital, and children's and parents' feelings of self-efficacy. Family well-being and student educational success are conceptualized as the broad outcomes discussed in this chapter 
in light of the literature connecting family well-being, parent engagement, and student academic achievement. The key mechanisms of change in the most plausible hypotheses were:

- Hypothesis 1: In the MSIC initiative, administrators who lead with a vision of social justice collaborate and share leadership responsibilities with families about school and community advocacy and decision-making, which encourages families' and school staff's feelings of a collective sense of ownership and investment in the school and community, which results in improved family well-being and student educational success.

- Hypothesis 2: In the MSIC initiative, administrators who do not lead with a clear vision of social justice do not collaborate with families to lead family and community engagement activities, encouraging parent perceptions that the school staff, families, and the community do not have mutually shared interests and goals, which results in a negative impact on family well-being and student educational success.

- Hypothesis 3: In the MSIC initiative, administrators who lead with a vision of social justice collaborate with families to share leadership responsibilities in family and community engagement activities with a diverse team of parent leaders, encouraging a greater sense of self-efficacy and empowering families, which results in improved family well-being and student educational success.

The causal chain of events in the present study was conceptualized as occurring in the following manner: the context (which included the program features and moderating conditions of the case study site[s]) encourages a change in family and school staff attitudes, beliefs, and/or preferences (mechanism of change), which in turn resulted in particular outcomes (see Figure 1). The manner in which certain activities and characteristics were conceptualized as mediators or moderators in this study may differ from the way other studies could conceptualize these. For example, social justice leadership is conceptualized here as a moderator and parent engagement 
is conceptualized as an outcome. Others might conceptualize these examples as mechanisms of change, resulting in a different causal sequence. The decisions about what was considered a moderator or a mediator in this study was informed by the data sources (i.e., secondary qualitative data, MSIC reports, and literature). Before presenting the findings of the explanatory analysis, the terms used throughout this chapter are operationalized below.

\section{Figure 1}

Conceptualization of the Hypothesized Causal Chain of Events

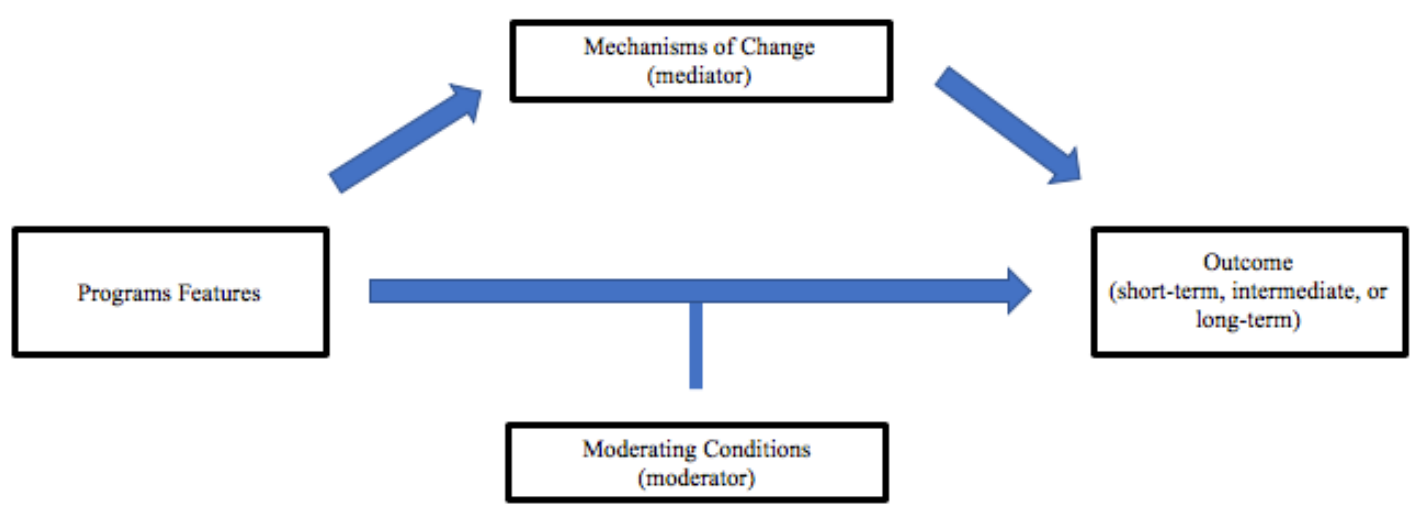

\section{Defining Context, Mechanism of Change, and Outcome}

\section{Context}

The context consists of the program features and the moderating conditions at the relevant case study site(s). These features and moderating conditions together provide the context in which the causal chain of events occurred.

Program Features. The program features included features of the MSIC initiative and the school-family-community engagement activities at the relevant case study site(s) that initiated the causal chain of events leading to the outcome.

Moderating Conditions. Baron and Kenny (1986) describe the moderator as the variable "that affects the direction and/or strength of the relation between an independent or predictor 
variable and a dependent or criterion variable" (p. 1174). Moderators include particular conditions under which the chain of events occur and can influence the relationship between the program feature and the outcome.

\section{Mechanisms of Change}

Mechanisms of change involve the mediating circumstances that lead to particular outcomes. Baron and Kenny (1986) state that mediators explain "how external physical events take on internal psychological significance" (p. 1176). Mediators, or mechanisms of change, typically involve a change in belief, preference, or reasoning triggered by an activity or stimulus under certain moderating conditions that in turn leads to a particular outcome (Wong et al., 2013). Unlike moderator variables that describe when certain effects will hold, "mediators speak to how or why such effects occur" (Baron \& Kenny, 1986, p. 1176).

\section{Outcomes}

The outcome is the dependent variable, or the final result of the chain of events.

According to Wholey et al. (2004) in a discussion of program evaluations, short-term outcomes are the direct result of an intervention or program feature and can lead to intermediate outcomes and ultimately result in long-term outcomes.

\section{Hypothesis 1: School Staff and Families Feeling a Collective Sense of Ownership and Investment in Family and Community Well-being}

Hypothesis 1: In the MSIC initiative, administrators who lead with a vision of social justice collaborate and share leadership responsibilities with families about school and community advocacy and decision-making, which encourages families' and school staff's feelings of a collective sense of ownership and investment in the school and community, which results in improved family well-being and student educational success.

Note that this hypothesis was relevant to MS1 and as such the following section reports data from MS1. 


\section{i. Context}

Program Features. The key features at MS1 that encouraged families and school staff to feel a collective sense of ownership and investment in family and community well-being included opportunities for advocacy through parent council, collaboration with the MSIC Community Support Worker, and parent engagement in decision-making. Beyond acting as an avenue for family-school staff communication, the parent council at MS1 also acted as an advocacy and fundraising group for community interests. For example, MS1 administrators and MS1 parents spoke about how the parent council's fundraising committee had raised funds for community causes. One MS1 administrator in 2014 explained that, "We have a fundraising committee... Last year they probably raised around $\$ 1000.00$ in total over the course of the year and this year they've probably raised closed to $\$ 2000.00$ for various initiatives.” The parent council at MS1 also took part in advocacy and even partnered with another local organization to advocate for priority access to neighbourhood programs for residents after noticing that nonresidents were registering. For example, one parent said:

[Resident access to local recreation programs] is something that the parent council was advocating for. And with help with another organization outside of our school we teamed up with we are trying to get that changed now. That the spots that do become available will be held for [community resident] kids first. (MS1 parent, 2019)

The MSIC Community Support Worker (TDSB, 2005; TDSB 2016) was an important resource for the parent council in their advocacy efforts. The MSIC Community Support Worker at MS1 assisted the parent council in organizing a school walk-out to protest provincial changes to public education policy and funding. For example, one MS1 parent explained:

We hooked up with [another community advocacy group] and we did the walk-out. And the [the MSIC Community Support Worker] let the other schools know what we were doing and gave them the petitions and things like that so he helped us facilitate that. (MS1 parent, 2019) 
Parents at MS1 were also involved in decision-making at the school through leadership on parent council and further engagement opportunities through the MSIC parent academy. An MS1 administrator in 2014 said that parents took "an active role in the implementation of a school uniform." Parents spoke proudly of their role in planning for the school uniform. Parents advocated for, voted, and decided to implement a uniform policy for the school.

Moderating Conditions. There were two noteworthy moderating conditions that influenced the causal chain of events in this hypothesis. Both a history of parent engagement and a vision of families as key partners in enhancing social justice and equity were key conditions under which a collective sense of ownership and investment for the school and community and family well-being was possible. MS1 administrators, both who had worked in the community for numerous years, reported that MS1 had a long history of parent engagement and advocacy. An MS1 administrator noted that, "historically, this school has always had a high level of parent involvement." Parents also noted this and one MS1 parent in 2014 said, "[MS1] has always had a nice parent council. We get a lot of parents." This history of parent engagement created a precedent and expectation for ongoing school-family-community collaboration. Any new parent or school staff joining the school community were immersed into an already established culture of family engagement.

MS1 administrators' social justice stance included equitable collaborations with parents, where parents held leadership and decision-making power and were viewed as key partners in working towards enhancing equity within their community. One MS1 administrator in 2019 explained that an important component of parent engagement at their school was that parents and the school share a vision of anti-oppression and social justice. For example, the MS1 administrator noted that: 
[An] anti-oppressive stance [is important]. The families understanding that equity and this notion that the school is the heart of the community is something that is part of the on-going work that we are doing. They are not just one-off's. It's at the core of what we do. (MS1 administrator, 2019)

For administrators at MS1, parents were viewed as key partners and co-leaders in enhancing equity and social justice in the school and community.

While there is research that highlights the importance of establishing equitable collaborations with parents (Ishimaru, 2019) and other research that has found that the extent of family engagement in schools is dependent on the commitment from the leader to include diverse stakeholders, including students and parents (Fuller et al., 2013), no research has yet tested or identified social justice leadership as a moderating condition of equitable collaborations with families. The notion of equitable collaboration with parents refers to collaborations that are built on reciprocal relationships where schools act in solidarity with nondominant families and marginalized communities in order to create systemic change (Ishimaru, 2019; 2020). The present study confirms social justice leadership as a moderating condition of equitable collaborations in schools. A finding unique to this study is that a school's history of parent engagement and relationships with families moderates the extent to which leaders share leadership responsibilities with parents.

Previous research has documented the power of a history of parental and communitybased leadership, but has not identified it as a moderating condition of shared leadership. In an example described by Ishimaru et al. (2016), a historically active parent council successfully advocated for the removal of a principal who was not willing to take part in equitable collaborations with families. Although not discussed explicitly as a moderating condition, Ishimaru's et al. (2016) study supports the notion that a history of parent and family engagement and advocacy sets the expectation for school leadership to engage in shared leadership with 
families. The present study confirms that a history of strong and equitable school-familycommunity engagement is a moderating condition of collaborative leadership.

\section{ii. Mechanism of Change}

Both MS1 parents and administrators spoke about how parent-led advocacy and shared decision-making made families feel a shared sense of ownership for the school and community. For example, one MS1 administrator noted that:

There is an initiative now in moving to uniforms and that's all sort of school [parent] council and families that lead that and [we] supported. They've taken on that initiative. They are invested. They want to make it happen. I think there is a greater sense of ownership to this space and that's a welcome piece to us. (MS1 administrator, 2014)

Leading the uniform initiative seemed to create a sense of ownership of the school space for families. The administrator also noted that when parents are willing to share decision-making power and help set the direction of the school activities, it demonstrates that parents are invested in the school. For example, the administrator commented that, "the willingness to provide feedback also speaks [to parents] being invested in this space. And [the other MS1 administrator] and I really push for that right." MS1 parents corroborated MS1 administrator comments and spoke about their sense of ownership of the school also. For example, in 2014, one MS1 parent said, “I go to [MS1], not my son. It's a pride thing for sure." In 2019, another MS1 parent said that "we do not move as a council without hearing from the parents here." The parent council was focused on parents' voices, and parents felt a sense of ownership over what happens in the parent council and in the school more generally.

Parents at MS1 had opportunities to advocate for community causes through established school structures, including the parent council. By encouraging parents to use school-based avenues and supports to partner with local agencies and advocate for community causes that were important to them, leaders sent a message to parents that the school was invested in the 
well-being of the community. This sense of investment is reflected in parents' comments, where they describe the school and community as partners. In 2014 one MS1 parent said that, "There's a partnership. It's not just the school and [the community]. The school actually does a lot with other organizations within [the community]."

The present study found that having opportunities to co-construct the school through shared decision making and encouraging parent-led advocacy for community encouraged families' and school staff's shared sense of ownership of and investment in the school and larger community. Similarly, Quiñones and FitzGerald (2019) and Ishimaru (2013) have suggested that when parents and school staff share decision-making power, parents feel a greater sense of ownership of and investment in the school. Further, Goldfarb and Grinberg (2002) found that community members felt a sense of ownership over their local community centre when they took part in decision-making processes about the community centre. The present study confirms feelings of ownership and investment as a key mechanism of change influencing families' engagement in school.

\section{iii. Outcomes}

MS1 parents and administrators reported that a collective sense of ownership and investment in the school and community led to improved family well-being and student educational success. Specifically, MS1 administrators spoke about an increase in parent engagement and student well-being as a result of parents' leadership in fundraising and advocating for community concerns. One MS1 administrator in 2014 explicitly said that the school had, "seen a higher level of parent involvement through school [parent] council" because of the council's focus on fundraising and involvement in planning for a school uniform policy. For example, an MS1 administrator said: 
... anytime you can get parents involved they get a greater sense of some of things that are going on in the building and then those conversations happen at home with their child right... They have a better understanding of some of the challenges, some of the rewards of what [we] see every day here. And they also now become an advocate on a different level for us. (MS1 administrator, 2014)

As parents become more engaged in the school, they also become co-advocates with school staff on issues that pertain directly to the school because they have a better understanding of what happens in the school and are more likely to talk about school with children at home.

Feelings of investment and ownership also had implications for student well-being. Another MS1 administrator said that when parents are engaged in the school in such a way that they are also advocating for and helping the local community, there is a greater sense of community cohesion. This MS1 administrator explained that when students see that the school cares about their families and their community, students themselves feel cared for and about. School staff's and parents' shared ownership and investment in both the school and the community resulted in a sense of belonging and care for students.

This analysis revealed that parents' feelings of ownership encouraged by shared decisionmaking in the school and co-advocacy for community causes resulted in outcomes for both parents and students. In line with these findings, Quiñones and FitzGerald's (2019) study of leadership practices at a community school in the USA suggested that parents' sense of ownership for the school resulted in higher levels of parent engagement. Unique to this study, a shared sense of ownership for the school and community amongst school staff and families was also found to be connected with a students' feelings of being cared for and about in the school. Parent engagement and students' sense of comfort and belonging in the school can be connected to longer-term outcomes of student academic achievement, as both have been documented to be connected with improved student academic success (Hernandez et al., 2014; Hughes et al., 2015; 
Jeynes 2005; Jeynes, 2007). Overall, this analysis provided strong support for the link between school-family shared leadership in community advocacy and decision making, families' and school staff's feelings of a collective sense of ownership and investment in the school community, and improved family well-being and student educational success.

\section{Hypothesis 2: Families Perceiving a Lack of Mutually Shared Goals Between School Staff and Families}

Hypothesis 2: In the MSIC initiative, administrators who do not lead with a clear vision of social justice do not collaborate with families to lead family and community engagement activities, encouraging parent perceptions that the school staff, families, and the community do not have mutually shared interests and goals, which results in a negative impact on family well-being and student educational success.

Note that this hypothesis was relevant to MS2 and as such the following section reports data from MS2.

\section{i. Context}

Program Features. The key features that resulted in MS2 families perceiving that the school did not have shared interests and goals included limited relevant parent engagement activities and limited opportunities for schools and parents to collaborate. MS2 parents described the parent workshops and events offered through the school as "safe" programs on topics such as building children's confidence or reading at home. MS2 parents discussed their desire for workshops and events to be more relevant to children's and families' experiences in the community. For example:

Parent 1: You know because this is where we live. It's a very high chance it will happen. Very high chance. Very high chance they'll get in a fight, a very high chance they are having sex behind the school, doing drugs whatever. We can't just say what if my daughter comes home and says she is pregnant, you know? Not what if I find out my daughter is having sex. What am I going to do once my daughter says she is pregnant. How are you going to deal with it? This is the kind of stuff, the kind of workshops I think we need to have. 
Parent 2: But they are having workshops on how to encourage your child to read. You know "safe programs" like you said. Everything is safe. (MS2 parents, 2019)

Parents highlight some of the community concerns they were grappling with at MS2, such as drug use and youth pregnancy. MS2 is located in a sprawling neighbourhood in Toronto where community services and programs were not generally located in walking distance from families' homes. Families needed to use city transit to access community centres and other social services. In comparison to more central, downtown neighbourhoods in Toronto, there are less social services in the local community for families at MS2. This may help to explain why there was a desire for more parent programming to address social determinants of health, like employment, at the school. There was evidence in 2019 that MS2 administrators were making efforts to offer school-based programs that may have been more relevant to parents' interests and concerns. For example, MS2 administrators spoke about offering workshops in partnership with local organizations on trauma and financial health. One MS2 administrator said that the financial health workshops were, "very well attended because that's what our community members wanted to know." In 2014 though, there was limited evidence of such programming.

Parents in both 2014 and 2019 noted some challenges in collaboration and sharing their desires and concerns with the school, although collaboration seemed to improve in 2019. In 2014, MS2 parents discussed a lack of comfort and avenues through which to raise their concerns with the school. For example, when MS2 parents discussed their concern about slippery ice in the school yard and student safety, one parent in 2014 said that they had not yet voiced their concern with the school because they did not know who to turn to. This MS2 parent in 2014 reported, 'I don't know who I'm going to tell. I'm going to tell the principal? Why don't you salt so they can go outside? I don't know." The parent council was noted by one MS2 parent in 2014 as an avenue through which parents can raise their concerns, but another parent said that the 
school staff who do attend the council do not engage in conversation with families. This MS2 parent in 2014 said, "[The school staff at the parent council] just sit there and don't talk."

In 2019, with the change in MS2 administration, there was a noteworthy increase in efforts from school staff to collaborate with families and hear their interests and goals for the school. For example, MS2 administrators described a monthly event series led by the MSIC Community Support Worker and a TDSB Settlement Worker (TDSB, 2005), where school staff gathered with parents over tea to chat about a topic that was mutually decided upon. One MS2 administrators described that:

Our [MSIC] Community Support Worker would arrange [the gathering over tea]. And they [the MSIC Community Support Worker] would ask the parents and community members what do you want? What do you want to see? What do you want to learn about? What do you want to chat about? Would you want to hear from the principal or the vice principal, teachers? (MS2 administrator, 2019)

Still, despite this desire and efforts to collaborate with families, not all parents felt these events addressed families' interests. For example, one MS2 parent in 2019 said that the events were only "glossing over the issues. [You] can't really get the real information, you know?" Evidence from MS2 parent focus group data indicated that MS2 administrators' efforts to collaborate and plan parent events seemed to largely take the form of informal conversations between parents and school staff, where parents were asked to speak to their parent peers about what type of programming might be helpful. For example, one MS2 parent in 2019 said:

They are asking me what do immigrants want. I don't know! How would I know what they want! I told you what I want and you still haven't given me what I wanted. So why are you asking me that? Ask them what they want. (MS2 parent, 2019)

Although the intention for collaboration with families seemed to be present amongst administrators in 2019, and indeed school staff were asking some parents about what they wanted to see happen in the school, a disconnect between parents desires and parent event 
offerings remained. Another MS2 parent also noted some resistance from staff when they did share their desires. This MS2 parent said:

There [are times] in our meetings [with school staff] and we [parents] say we want to talk about, [for example], the sex education curriculum... [But the school staff respond] "Oh we don't want to talk about that. That's sensitive." Okay fine, let's talk about gender and the washrooms. Let's talk about something real, please. (MS2 parent, 2019)

While collaboration efforts with parents improved in 2019 in comparison to 2014, this parent's comment highlights that the school and parents were still working to establish mutually shared interests and goals.

Although the parent council was mentioned by both parents and administrators at MS2 in 2019, it was not explicitly spoken about as an avenue through which to share parents' concerns with the school or as a group that collaborates to plan parent engagement activities. An MS2 administrator in 2019 said that the MS2 parent council's main role was leading a pizza lunch program in the school. In relation to the parent council, an MS2 administrator in 2019 noted that, "It [the parent council] fluctuates [in terms of] how many people attend every month depending on work schedules and everything. But we do have a core ...- we do have pizza lunches. They do organize pizza lunches." It appeared that, overall, MS2 administrators' efforts to collaborate with parents about school events relied on informal conversations with families more so than through parent council.

This focus on one-on-one conversations with families is reflective of the MS2 administrators' general efforts to develop strong, trusting relationships with individual parents in 2019. MS2 administrators had only been at the school for a few years in 2019 and they spoke about how much of their efforts around parent engagement were focused on building trusting relationships with individual families. Building these relationships is an ongoing process with different groups of families, that takes time and might help parents to feel more comfortable to 
engage in more intentional and collaborative parent-school planning groups later. At the time of the interview, though, those trusting relationships were in the process of being built.

MS2 administrators' increased efforts to offer more relevant workshops for families and strides were toward greater collaboration between families and school staff in 2019. With a long school history where parents may have had limited opportunities to raise their concerns with the school, more time may have been needed to establish and build awareness around avenues for family-school collaboration.

Moderating Conditions. Moderating factors operating in this hypothesis included administrator vision of social justice, community context, and staff turnover. The administrators' vision of social justice at MS2 changed between 2014 and 2019, where the administrators in 2019 spoke more often and more explicitly about social justice and equity. In 2014, MS2 administrators recognized systemic issues that impacted the community (e.g., high youth pregnancy rates, addiction, unemployment). For example, one MS2 administrator noted that:

I think one of the greatest challenges is the history of the community and the poverty, the disenfranchisement, the generational poverty and recidivism in the community where you have parents who have gone through this school who have children who have gone through this school and the grandparents might have you know. And a very young community in that we have a lot of young mothers and there is a lot of very concentrated buildings in a small area that has no services really around them. To get to [i.e. travel] anything is a bit of a feat. It's not a well-planned situation. (MS2 administrator, 2014)

Although MS2 administrators spoke to the challenges facing the community in 2014, they did not speak about how the school worked with parents to address these systemic issues, except for describing that they had a breakfast and snack program to improve food insecurity, along with a food sharing program offered in partnership with a community organization. In 2019, MS2 administrators did adopt a greater social justice lens, where they recognized the potential of the school as a place to provide additional extra-curricular and social opportunities for children and 
families that were not readily available in the local community. One MS2 administrator in 2019 said, “Our kids don't have the opportunities outside of school [so] let's give them the opportunities here, right? So equity [in access to] resources [and] opportunities.” This social justice stance helps to explain MS2 administrators' openness and willingness to offer more relevant parent events at the school that addressed community challenges.

Community context was also an important moderating condition operating in this hypothesis. Unlike MS1 where there were "so many amazing [community] groups that are right literally in our back yard” (MS1 administrator, 2014), families at MS2 lived far from and had fewer nearby community services, such as libraries and community centres. MS2 parents in 2014 and 2019 spoke about a lack of childcare centres, before and after school programs, and extracurricular opportunities for families in their neighbourhood. Due the lack of local services, parents' desire and need for school-based services was more pronounced in comparison to schools that had more services in their local area.

Staff turnover rate was another moderating condition operating in this hypothesis. MS2 had a high staff turnover rate of both teachers and administrators. For example, one MS2 parent in 2019 said, "Unfortunately it's been like a revolving door [of staff] here." Parents noted that this high staff turnover rate caused a barrier in building relationships with school staff. In 2019, MS2 administrators had only been at the school for a couple of years and spoke about spending much of their time building one-on-one relationships with families. As MS2 administrators in 2019 noted, building trust takes time. For example, one MS2 administrator said:

You know it takes a while to trust. As we were saying with supply teachers, when they are on a day to day basis or whatever, it takes a while for them [students] to establish that trust with an adult right. Even the parents too. It took them awhile to trust us [school staff]. Who are you? You are both new. You don't look like us. What do you know about our community? (MS2 administrator, 2018) 
The high staff turnover rate at MS2 was a moderating condition in that the staff turnover negatively impacted parent-school staff relations, which limited the collaboration opportunities for school staff and families to talk about their interests and goals.

The leaders' social justice vision, the community context, and staff turnover were all moderating conditions that impacted the degree to which the school could collaborate with families to offer relevant parent workshops and events. Social justice leadership goes beyond only recognizing the systemic inequities affecting students, families, and communities and includes actively working to create more socially just schools and communities (Theoharis, 2007). Previous research corroborates the present study's findings which highlight the importance of a social justice stance and has attested that social justice leadership is required for establishing the school as a place that actively addresses out-of-school challenges (DeMatthews et al., 2016; Theoharis \& O'Toole, 2011). In line with the moderating condition of staff turnover, the study by Medina et al. (2019) investigating the effectiveness of Full-Service Community Schools in Indiana found that administrator and teacher turn-over in low-income neighbourhoods with high populations of students of colour resulted in "fractured relationships" between schools and students and diminished trust between schools, parents, and communities. As the present study highlighted, trusting relationships may be important for ongoing school-parent collaboration in planning school events. In addition to social justice leadership and staff turnover, the lack of available social support services in the neighbourhood was a significant community-level contextual factor in that there was an amplified need and desire for the school to address family and community concerns, such as unemployment and poverty at the school. 


\section{ii. Mechanism of Change}

There was evidence that MS2 families perceived a mismatch between their goals and interests and the school's goals and interests, largely due to the limited relevant programs and events for parents and the limited collaboration about the topics of those events. For example, one MS2 parent spoke about how the school offering courses on financial health ignored the core issues of unemployment and poverty in the community. This MS2 parent shared that they think:

[that] the programs they [MS2] run are safe programs. No one gets upset you know. You said like it - this community is not an easy one. We need to have something that will deal with the problems in this community. People in this community are, a lot are on welfare or single parent families. Even if it is a two-parent family you are living by the pay cheque. What financial health? Like, I have nothing to invest. I go to the program but it's not doing anything for me. I have no money to invest. I can't buy a house. (MS2 parent, 2019)

In comparison, MS2 administrators in 2019 thought that these financial health events focused on "saving for post-secondary," "managing debt," and saving for retirement were helpful for families. These events may have been helpful for some parents, but not for all. Although both MS2 administrators and parents recognized a need for workshops for parents around finances, the comments by the MS2 parent above highlight a need for a greater focus on addressing more foundational community challenges, such as employment security.

MS2 administrators in 2019 recognized that parents' voice in decision-making around the type of engagement events and activities was important. One MS2 administrator in 2019 said:

So a lot of [the planning], as I said, is through [the] community. Asking what [they] want to make sure that they come, right? So we are not going to decide we are going to do this topic because we feel that this community needs that, no. (MS2 administrator, 2019)

MS2 administrators in 2019 did not view themselves as experts on the community concerns, and to ensuring the events would be relevant to families, they worked to hear what families wanted. 
Although MS2 administrators in 2019 were willing and eager to collaborate with parents, some parents felt more collaboration could happen. For example, one parent said:

Parent 1: Give me what I want. You are bringing me to a meeting to tell me how to read and understand my child's report card. I understand that's important but that's not what I am leaving my house for. Give me what I want. What do I want. That's the question. Ask them [parents] what they want... and then provide it and let them attend. It's just common sense. Everything is very simple but it seems like it is so complicated and sometimes it just becomes about numbers. We have five people attend, we are doing well. Parent 2: That's true.

Parent 1: Who cares! Half of them were teachers! (MS2 parents, 2019)

In addition to desiring more opportunities to share their thoughts about parent events, these MS2 parents questioned the school staff's goals and intentions in hosting events and workshops for parents. They wondered whether the school staff's intentions are to have high parent attendance to prove that they have parent engagement, rather than address core parent and community concerns. There was evidence, though, that MS2 administrators had family and community wellbeing in mind in their collaborations and planning of events. It is possible that these parents' skepticism around school staff intentions were rooted in historic feelings of distrust between the school and parents. Considering the school's history of staff turnover, MS2 administrators were still building trust with parents in 2019 upon which more co-planning around parent events and workshops could happen.

Overall, these findings highlighted a mismatch between MS2 administrators' and parents' perceptions of families' and the community's interests as well as perceived differences between administrators' and parents' intentions or goals of parent engagement activities. While MS2 administrators made efforts to collaborate with parents and offer relevant workshops and events in 2019, MS2 parents expressed a desire for more collaboration and relevant programming that directly addressed parent and community concerns. Previous research has demonstrated the importance of having opportunities for families to collaborate and share leadership roles with 
school staff in ways that parents are positioned as experts and the shaper of services and programs that schools offer (FitzGerald \& Quiñones, 2019; Ishimaru, 2018; Peterson \& Durrant, 2013). Whether it be through parent council, surveys, or family and community forums, parents and school staff can learn about community concerns and establish service and program goals together (Patel et al., 2008; Peterson \& Durrant, 2013). Further, scholars have noted the importance of having various two-way forms of communication and opportunities for parents to engage, not only through formal governance like parent council, but also in more informal oneon-one conversations with parents (Patel et al., 2008). There was evidence of parents and school staff at MS2 engaging in some two-way communication, yet some MS2 parents still perceived a lack of congruency between the school's and families' interests and goals. Asking families what they want, or what their goals are in service provision is key in building supportive school-based services and building relationships with families (Patel et al., 2008).

\section{iii. Outcomes}

Ultimately, this lack of congruency between the school's and families' interests and goals leads to negative impacts on family well-being and student educational success. Due to a lack of shared interests and goals between the school and families at MS2, there was decreased parent engagement among families. One MS2 parent said that parents stop attending school events when they notice that the goals of the school staff are different from their own and when programs do not help their family's well-being and quality of life. The parent shared that they, "just want to know if you [the school] are really for us and what are you doing about it to help us get ahead in life? Bottom line" (MS2 parent, 2019). Although parents did not explicitly speak about how decreased parent engagement negatively impacts student educational success, 
previous research has demonstrated that parent engagement positively impacts student academic achievement (Jeynes, 2005; Jeynes, 2007).

MS2 parents talked about some of the core challenges in their community, including for example, community safety (i.e. not wanting to be away from their children outside of school hours) and employment. A parent noted that if the school had more workshops, events, and programs that address the core concerns of families, there would be more parent engagement. This MS2 parent said:

If you said this - the first 100 people sign up for a program this morning, 9 o'clock, we are giving everybody 50 bucks and we are going to train you on how to get some type of employment that can be done in the hours of when your child is in school. Meaning that you can also pick up your child for lunch and you will 100\% not be away from your child at any time and we will pay you and you are going to be contributing to society and you can do this as a career and you can make it in life. You would have so much friction in this room, believe me. You wouldn't be able to breathe. You would have to call the fire department because of the overflow of people in this room. We are not getting what we need, not just want, need. (MS2 parent, 2019)

In a community where there is a lack of locally available social services and supports for families, the school can become a site of support and partnership with families to address those community-level concerns and help to improve family well-being. Through collaborating with parents to get to know their needs and goals, as was beginning to happen in 2019 at MS2, school staff can have a better understanding of the lived experiences of families and partner with parents to offer relevant programming that improves family well-being. While previous research has shown that schools can act as sites of social brokering that strive to increase parents' social capital (Green, 2018; Galindo et al., 2017; Newton et al., 2017), the present study's analysis highlights the importance of collaboration and parent leadership in developing school-based social brokering and parent engagement activities to ensure that they align with the interests and goals of families and communities. Overall, this analysis provided moderate support for the link 
between limited school and family collaboration and parents' perceptions of a lack of congruency in school staff's and families' interests and goals. This results in negative impacts on family well-being and student educational success.

\section{Hypothesis 3: Families Feeling Empowered and a Sense of Self-Efficacy}

Hypothesis 3: In the MSIC initiative, administrators who lead with a vision of social justice collaborate with families to share leadership responsibilities in family and community engagement activities with a diverse team of parent leaders, encouraging families' feelings of empowerment and greater sense of self-efficacy, which results in improved family well-being and student educational success.

Evidence related to this hypothesis appeared in both MS1 and MS2 data. Both are reported below.

\section{i. Context}

Program Features. Key features that encouraged feelings of empowerment and a sense of self-efficacy included parents' leadership role on the parent council and in MSIC Cluster Parent Academy Committees (CPAC), parents leading family and community engagement events, and the presence of a MSIC Community Support Worker. Participating parents at MS1 took on leadership roles in their parent council. MS1 parents held power in parent council meetings and set the direction of the council's activities. For example, in commenting about the parent council one parent said that:

It [the parent council] is the forum where the parent's voice is heard. I think that's what I like the most. It's not about what the principal wants or what the teacher's want. It's what we the parents want... This is their platform to stand and say whatever [we] need to say. (MS1 parent, 2019)

This parent highlighted that although school staff may be present at parent council meetings, parents led the meetings. One MS1 parent spoke about how parents also took a leadership role in the MSIC CPAC. MSIC CPACs bring together parent school representatives from several different schools within a 'cluster' geographic boundary to determine parent programs and 
discuss topics relevant to the school communities within the cluster (TDSB, 2014). This MS1

parent noted that MS1 administrators would attend these parent-led monthly meetings to listen to parent concerns. In 2019 this MS1 parent explained:

The [MSIC] CPAC is 23 schools with all parents representing the 23 schools plus [administrators] who volunteered there. [The MS1 administrator] used to come and he used to hear [our stories]... the parents, newcomer and how they suffer and equity [issues]. (MS1 parent, 2019)

The MSIC CPAC was described by this parent as a place where parents took the lead and school staff came to listen.

MS1 parents also took a leadership role in the planning and implementation of parent and family engagement events. For example, with the support of the MSIC Community Support Worker, MS1 parents lead events where the parent council brings in a speaker to discuss a topic that parents are interested in. Parents reported that sometimes the agenda at the parent council is full that they will use this event, which included refreshments for parents, as an opportunity to discuss topics they cannot fit into parent council meetings. MS1 parents described how they collectively determine the topics of the events:

Parent 1: The parents say usually at the beginning of the year we wanted to talk about A, $\mathrm{B}, \mathrm{C}$, and D. We did a special needs one. Food handling. Parent 2: The last one we did a mediation/conflict resolution. The staff like it and the [MSIC] Community Support Worker, he is the one that did that and I helped him. (MS2 parents, 2019)

MS1 parents appreciated the MSIC Community Support Worker's support in planning and facilitating these events. The MSIC Community Support Worker's role is to support parent and community engagement at the school. For example, one MS1 administrator said:

The [administrator] job is so multi-faceted. There is so many different pieces that we have to manage and so having someone [the MSIC Community Support Worker] that it is their assigned job to promote parental engagement and that I can delegate certain tasks to is very helpful to ensuring that things get done. (MS1 administrator, 2019) 
MS1 administrators appreciated the MSIC Community Support Worker's efforts to engage families. MS2 administrators also spoke to the important role of the MSIC Community Support Worker in their school and viewed their MSIC Community Support Worker as integral to "promoting parental engagement" at MS2. Although MS2 had a historically less active parent council than MS1, MS2 parents spoke about feeling empowered by the connection that the MSIC Community Support Worker facilitated for families. For example, one parent noted that:

Our community worker... she's like the chain that links us all. And she has brought Social Workers to speak to us, like the people who are dealing directly with our children who we've never met... she's brought Education Ministers that we would never meet or even know their names. She's brought them to the table with us. She's brought so many people to our little school to ask us what do you need. (MS2 parent, 2019)

The MSIC Community Support Worker at MS2 facilitated parents' connections with individuals from the social and educational systems and allowed parents to lead those conversations.

Moderating Conditions. Administrator attitude towards social justice and parent engagement was a noteworthy moderator operating in this hypothesis. The MS1 administrator spoke often and explicitly about their social justice stance and work around anti-racism and antioppression. This was reflected in their practices around giving power and voice to nondominant families through the school's parent council. MS1 administrators in 2019 spoke about how they intentionally ensured, "that the composition of the executives of [the parent] council reflects the diversity of the community." This MS1 administrator noted that:

I've seen in many schools [where] the [parent council] executive will reflect the dominant culture. And in our school it's not like that. We've got families that have been in [the community] for a number of years that are on our executive. We have some newcomer families. We have got a range of cultural backgrounds and again that was constructed intentionally. (MS1 administrator, 2019)

MS1 administrators in 2019 made targeted recruitment efforts to dismantle traditional systemic hierarchies, distribute power, and ensure that the parent council was not dominated by, 
"Caucasian families with lots of degrees behind their name." Administrators at MS1 were aware that parent leadership on the parent council could be an avenue to perpetuate inequity and give power to the dominant, white, upper middle-class culture. MS1 administrators' social justice vision increased opportunities for co-leadership and encouraged more parents to be engaged in the parent council.

There was a noteworthy difference between MS1 and MS2 administrators' visions of and attitudes towards parent engagement. At MS1, administrators viewed families as key partners and leaders in co-constructing the school and larger community alongside school staff. One MS1 administrator in 2014 noted that:

I think what we want to get away from is this notion that our families are always needing help and needing to be the recipients of services and yes there are a high number of needs in this school [and] in the community but our families of kids are very capable of giving back [to the school and community]. (MS1 administrator, 2014)

MS1 administrators viewed their school's families as active participants in contributing to the well-being of the school and community. In comparison, at MS2 in 2014, one MS2 administrator seemed to view parents as uninterested in engaging in the school and felt there were few ways to encourage engagement. This MS2 administrator in 2014 said that, "There is not community involvement in the school [MS2]. They [families] won't come out to events unless, you know, there is a jumpy castle involved. Even with food they won't come out sometimes.” This MS2 administrator's attitude towards parent engagement moderated the degree to which they shared leadership with parents. In 2014 at MS2, there was limited evidence of parent leadership in the school. In 2019 at MS2, though, MS2 administrators seemed to have a more positive attitude towards social justice and parent engagement. For example, one MS2 administrator noted that:

[Other schools'] parent councils fundraises thousands of dollars to purchase things for their school or give opportunities [for students]... [We used] part of [the MSIC Initiative] budget for a [partnership with a local organization] where they came in and did.... three 
days of dance. The entire school from kindergarten right to grade 8 and it was culturally diverse dances... Like I said in other schools often that would be through fundraising, through the parent council. But because we don't have that, we really rely on our model schools budget to give these opportunities to our students. (MS2 administrator, 2019)

This MS2 administrator's comments highlights their appreciation for the MSIC budget in allowing them to offer partnered programming to help address inequities. The administrator understood that families at MS2 may be engaged in ways that are different from other schools in more affluent communities. This MS2 administrator notes that their parent council, unlike other schools, may not be able to fundraise thousands of dollars for their school within their own community due to the neighbourhood socioeconomic level. Although both MS1 and MS2 both sat high on the TDSB's LOI, which measures social and economic challenges affecting student success (higher score reflects greater socioeconomic challenges), the MS2 local community had fewer nearby social services than MS1, which may have amplified existing social challenges for MS2 families. Combined with a history of limited parent engagement and a lack of available local partners to support school-level fundraising or advocacy led by parents, it is not surprising that despite the social justice stance of the MS2 administrator and overall positive attitude towards parent engagement in 2019, the MS2 parent council was not yet able to operate at its fullest.

The present analysis reveals that a leader's positive attitude towards social justice and parent engagement are essential conditions under which all parents, including parents from nondominant cultures, take on leadership roles in school activities and events. Similar to the findings at MS1, Theoharis and O'Toole (2011) documented social justice leaders making intentional efforts to ensure their parent council includes the voices of nondominant groups and even offered additional council meetings, that they called "parent empowerment groups" (p. 664), in languages other than the dominant language of the school. These efforts provided 
important opportunities for school staff to listen to the specific concerns of nondominant families and increased levels of nondominant parent engagement in both the parent council and the parent empowerment groups, ensuring nondominant parent voice was included in parent school leadership. The present study highlights that a leader's attitude towards both a social justice as well as parent engagement determines whether they will distribute leadership responsibilities to parents and intentionally create school structures through which nondominant groups' voices are elevated.

\section{ii. Mechanisms of Change}

Both MS1 and MS2 parents and MS1 administrators noted that having opportunities to take on a leadership role in the parent council and in planning school events, as well as opportunities to collaborate with the MSIC Community Support Worker, encouraged families' feelings of empowerment and a greater sense of self-efficacy. One MS1 administrator in 2014 said that taking the lead in parent council and school and community initiatives was, "a lot more empowering [families] than always just being the recipient of services.” At MS2, parents spoke about feeling empowered when the MSIC Community Support Worker created space for parents to lead conversations with representatives from social services and the education system. One MS2 parent in 2019 said that these conversations, "makes us feel empowered and understand that our voices are heard... it's a blessing for myself to see that you know what? Our voices matter." Another MS2 parent in 2019 said, "In terms of empowering the parents, the MSIC Community Support Worker, she has been doing an excellent job of that." MS1 parents noticed and appreciated the diversity of the MS1 parent council and thought it helped to make parents feel more comfortable and empowered to take leadership roles themselves. For example, one MS1 parent spoke about how he is on the parent council at his son's high school and found the 
lack of diversity in the council, where there were mostly "lawyers", intimidating, but felt more comfortable on the parent council at MS1. Another MS1 parent said:

You cannot go into a school meeting and be the only one. It's literally impossible because we are so diverse and I think that gives them [parents] a bit of comfort. Saying okay I'm not the odd one out. And they just start talking. It's like, I don't know how it's like, they just find the voice and I just love to sit back and say you know what I remember you when you first came. You were like don't look at me. You know? And then you just see them take on that leadership role and just they are off and running. (MS2 parent, 2019)

This MS1 parent's comments highlights that as parents feel more comfortable in the parent council, they feel more empowered to continue to take on leadership roles. MS1 administrators in 2019 corroborated this observed shift in parents' leadership role. One MS1 administrator said:

Now that we have had that [a diverse parent council] in place for a couple of years it serves as an example to other families and they say, if she can do it then I can do it. And they are now putting themselves forward without me having to kind of nudge them as much. (MS1 administrator, 2019)

By seeing themselves reflected in a diverse parent council, parents were more engaged and willing to take on leadership roles themselves.

MS1 parents explicitly spoke about how participation in the parent council influences parents' feelings of confidence. For example, one parent said:

I think [the parent council is] a great start to get that parent's confidence to know you are being heard. We hear you. How can we move forward? How can we put your vision into place and then we take it from there. But the parents in our council they are the ones that hold the power. They are the ones that set the direction of the council. (MS1 parents, 2019)

When parents have the opportunity to take a leadership role and hold power in parent council, parents' feelings of self-efficacy and confidence grows.

In sum, parents felt empowered when the school's diversity was reflected in the leadership roles, in planning and leading school events, and when the MSIC Community Support Worker created spaces for parents' voices to be elevated. These findings confirm the link between parent leadership and feelings of empowerment speculated by other researchers (Adams 
\& Jean-Marie, 2011; Ishimaru, 2013) and highlights the importance of having nondominant groups reflected in parent council leadership roles. The findings in the present study also highlight from the perspective of parents the important role of the MSIC Community Support Worker play parents' feelings of empowerment. In FitzGerald and Quiñones' (2018) study on a community liaison in a community school, where both parents and community liaisons were interviewed, it was found that the community liaison identified parent empowerment as part of their role construction, however, parents did not explicitly link feelings of empowerment to the work of the community liaison. The findings in the present study confirm, from the voices of parents themselves, that the work of community liaisons encourage parents' feelings of empowerment. In addition to feelings of empowerment, parents spoke about how taking on leadership roles in the school positively impacted their feelings of confidence and self-efficacy.

\section{iii. Outcomes}

This sense of empowerment and self-efficacy leads to improvements in family well-being and student educational success. For example, one MS1 parent noted how when parents feel empowered through participation in parent council, parents' parenting practices and student academic achievement improve:

They [parents] have their voice and they are able to use their voice [in parent council]. They feel more confident in what they are saying... And you just seem them like a flower. They are tight at first and then they just bloom. And it expands to everything they feel, they feel like that at parent council so they feel a little bit better about their parenting which shows on their child and the child shows it on their class and then the teacher sees it. It's like wow you can see just the transformation come. (MS1 parent, 2019)

This parent continues to explain that those feelings of empowerment and self-efficacy from taking on a leadership role in the school, "rebounds every part of their [parents'] life. Their home life, their school life, their work life, the community life. You just see it light up." Researchers have suggested that as parents participate in leadership activities at the school, their leadership 
and system navigation capacity improve, and they become empowered to be activists for school and community improvement (Ishimaru et al., 2016; Ishimaru, 2018). Research also supports the positive connection between parents' feelings of self-efficacy and parent engagement in school (Hoover-Dempsey \& Sandler, 1997; Ice \& Hoover-Dempsey, 2011) which, in turn, influences student academic achievement (Jeynes 2005; Jeynes, 2007). Further, researchers have found that respectful staff-parent relations and integrated services improve parents' feelings of self-efficacy, especially for immigrant parents (Patel \& Corter, 2013). The present study confirms that when leaders with a vision of social justice create opportunities for parents, particularly nondominant parents, to take on leadership roles in school-family-community partnership activities, and when community support workers or community liaisons respectfully work with parents to elevate parent voices, parents feel more empowered and a have greater sense of self-efficacy. These feelings of empowerment and a greater sense of self efficacy result in improved family wellbeing and student educational success. Overall, this analysis provided strong support for the link between school-family shared leadership, families' feelings of empowerment and self-efficacy, and improved family well-being and student educational success. 


\section{CHAPTER 4}

\section{Conclusion}

This explanatory multiple-case study aimed to answer Epstein's (2011) call for more confirmatory research on the mechanisms of change that connect school-family-community partnerships and student and family outcomes. Through investigating the role of leadership at two school sites in Toronto that are part of the MSIC initiative, the present study revealed some key strategies and practices leaders use to foster school-family-community partnerships. Through an explanatory analysis, this study confirmed that shared leadership practices in schools in the MSIC initiative result in improvements in family well-being and student educational success. Families' sense of ownership and investment in the school and community as well as families' feelings of empowerment and self-efficacy were identified as key mechanisms of change through which this causal link occurred. Conversely, when shared leadership practices are diminished, family well-being and student educational success are negatively impacted, with families’ perception of a lack of congruency in school staff, family, and community interests and goals as a mechanism of change. Some important conditions that moderated these causal links included, most prominently, the leader's attitudes towards and vision of social justice, as well as a history of family engagement at the school, community context, staff turnover, and administrator attitudes towards family engagement. Both the descriptive and explanatory analyses offer some important implications for future practice and research:

- An important first step in fostering school-family-community partnerships is creating a welcoming social and physical school environment (e.g., Auerbach, 2010; Barr \& Saltmarsh, 2014), fostering a culture of care and trust within the school (e.g., Bryk \& Schneider, 2002; DeMatthews et al., 2016; Khalifa, 2012), and having various avenues 
for frequent, reciprocal communication with families and community members (López et al., 2001; Patel et al., 2008). These strategies together establish an inviting atmosphere built upon trusting relationships between school staff and families and set the foundation on which future family and community partnerships and engagement can be built.

- Administrator vision may play a role in the degree to which schools address systemic inequities and operate as social and cultural brokers for families. The descriptive findings of the present study suggest that an administrator's vision of the school as a site for social and cultural brokering and a leader's social justice stance may influence the ways schools in fact act as social and cultural brokerages and address systematic inequities. This finding is not particularly surprising given past research on social justice leadership and administrator attitudes towards partnerships (e.g., DeMatthews et al., 2016; Muijs, 2007; Theoharis, 2007). However, additional explanatory studies are required to uncover the paths that connect leadership vision to the establishment of schools as sites of social and cultural brokering and as places that can enhance equity for students, families, and communities.

- The MSIC Community Support Worker emerged as an is important leader in terms of acting as a cultural broker for families and in co-advocating for community causes alongside families, despite this study's focus on the administrative leadership team (principal and vice-principal). Previous researchers have highlighted the importance of community liaisons in fostering school-family-community partnerships, particularly for nondominant groups (e.g., FitzGerald \& Quiñones, 2018; Ishimaru, et al., 2016). Future research on the MSIC initiative should include the perspectives of MSIC Community 
Support Workers and further unpack their leadership roles in supporting school-familycommunity partnerships.

- Place, in both a temporal (e.g., a school's history of parent engagement) and geographical (e.g., a school's location in relation to other community services) sense, must be considered in planning effective leadership strategies for school-family-community partnerships. Shared leadership models and equitable collaborations among school staff, families, and communities (Ishimaru, 2020) can ensure schools offer relevant services, resources, and programming for students, families, and communities. Schools provide families with important social supports, particularly families in communities with scarce or spread out local social and health services. School leaders with a vision of social justice and positive attitudes towards parent and community engagement who strive to address community concerns in collaboration with families are especially key in these communities.

- Leaders with a vision of social justice are essential to ensuring schools share leadership with families, thereby increasing family engagement in school and improving family well-being and student educational success. This has implications for both administrator hiring and training. A leader's social justice vision should be considered when hiring, specifically in inner-city contexts. The MSIC initiative offers anti-oppression and antiBlack racism training for administrators as well as family and community engagement training (TDSB, 2019a; TDSB, 2019b). It is crucial that all administrators in the MSIC initiative take part in family and community engagement and equity training with a key focus on shared leadership strategies in order for schools to effectively support family well-being and student educational success. 
Along with these implications and recommendations, some noteworthy limitations of the present study offer opportunities for future research. First, leading with a vision of social justice and equity was conceptualized as an unchanging moderating condition in this study. Future research should look at how vision might change overtime and how social justice and equity training may influence leadership vision. Further, additional research could investigate how leaders' conceptualizations and understandings of social justice differ, and how these differences may influence leadership strategies. Secondly, this study did not include the perspectives of MSIC community partners, MSIC Community Support Workers, teachers, students, or other school staff who play important roles in fostering school-family-community partnerships. Centring these voices in future research would deepen understandings of the causal pathways between leadership, school-family-community partnerships, and student, family, and community outcomes. Thirdly, this study did not focus on the role leaders' individual racial, cultural, and privileged identities played in their leadership strategies for school-family-community partnerships. Previous research has suggested that these identities influence leadership styles and practices (Hernandez et al., 2014; Shah, 2018a). Future research should consider what moderating role leadership identity may play in these pathways. Fourthly, the recruitment strategy in the present study changed between 2014 and 2019, where the recruitment in 2019 was purposefully targeted at sampling parents who were more actively and physically engaged in their child(ren)'s school. This change in sample may have played a role in the change noted in parent perspectives of school-family-community partnerships at MS2 between 2014 and 2019. Future research could continue to investigate and identify the various ways that parents participate in school-family-community partnerships in schools with social justice leadership (i.e., beyond parents being physically involved in school or involved in parent council). Finally, 
these data were not collected during the COVID-19 pandemic but were analyzed during the pandemic. Future research should consider how systemic inequities increase a lack of access to school supports for family health and well-being, during physical distancing and isolation. The present study confirms that schools in the MSIC initiative are sites of essential social and health related supports for families and communities.

Social justice leadership that fosters school-family-community partnerships is key to ensuring that schools in the MSIC initiative continue to enhance equity for students, families, and communities across Toronto. The voices of families and school leaders shared in this study ask educators, administrators, and system leaders to both listen and take action to create greater equity for children, families, and communities. 


\section{References}

Adams, C. M. (2019). Sustaining Full-Service Community Schools: Lessons from the Tulsa Area Community Schools Initiative. Journal of Education for Students Placed at Risk, 24(3), 288-313. https://doi.org/10.1080/10824669.2019.1615924

Adams, C. M., \& Jean-Marie, G. (2011). A diffusion approach to study leadership reform. Journal of Educational Administration, 49(4), 354-377. https://doi.org/10.1108/09578231111146452

Auerbach, S. (2010). Beyond coffee with the principal: Toward leadership for authentic schoolfamily partnerships. Journal of School Leadership, 20(6), 728-757.

https://doi.org/10.1177/105268461002000603

Baron, R. M., \& Kenny, D. A. (1986). The moderator-mediator variable distinction in social psychological research: Conceptual, strategic, and statistical considerations. Journal of Personality and Social Psychology, 51(6), 1173-1182.

http://dx.doi.org.ezproxy.lib.ryerson.ca/10.1037/0022-3514.51.6.1173

Barr, J., \& Saltmarsh, S. (2014). "It all comes down to the leadership": The role of the school principal in fostering parent-school engagement. Educational Management Administration \& Leadership, 42(4), 491-505. https://doi.org/10.1177/1741143213502189

Bryk, A. S., \& Schneider, B. (2002). Trust in schools: A core resource for improvements. Russell Sage Foundation.

Burbules, N., \& Berk, R. (1999). Critical thinking and critical pedagogy: Relations, differences, and limits. In T. Popkewitz \& L. Fendler (Eds.), Critical theories in education (pp. 4563). Routledge 
Caldas, S. J., Gómez, D. W., \& Ferrara, J. (2019). A comparative analysis of the impact of a Full-Service Community School on student achievement. Journal of Education for Students Placed at Risk (JESPAR), 24(3), 197-217. https://doi.org/10.1080/10824669.2019.1615921

Chaskin, R. J., Brown, P., Venkatesh, S., \& Vidal, A. (2001). Building community capacity. Aldine de Gruyter.

Cohen, L., Manion, L., \& Morrison, K. (2017). Research methods in education ( $8^{\text {th }}$ ed.). Routledge

Cohen-Silver, J. Laher, N., Freeman, S., Mistry, N., \& Sgro, M. (2017). Family fIRST, an interactive risk screening tool for families in a school-based pediatric clinic: A look at feasibility and pilot data. Clinical Pediatrics, 56(3), 217-225. https://doi.org/10.1177/0009922816657152

Coleman, J. S. (1988). Social capital in the creation of human capital. American Journal of Sociology, 94(1), 95-120. https://www.jstor.org/stable/2780243?origin=JSTORpdf\&seq $=1$

Cook, T. D., Murphy, R. F., \& Hunt, H. D. (2000). Comer's School Development Program in Chicago: A theory-based evaluation. American Educational Research Journal, 37(2), 535-597. https://doi.org/10.2307/1163533

Comer, J. P., \& Emmons, C. (2006). The research program of the Yale Child Study Center School Development Program. The Journal of Negro Education, 75(3), 353-372. https://www.jstor.org/stable/1163533?seq=1 
Corter, C., Janmohamed, Z., Pelletier, J. (2012). Toronto First Duty: Phase 3 report. https://www.oise.utoronto.ca/atkinson/UserFiles/File/About_Us/About_Us_What_We_D o_TFD/TFD_Phase3Report.pdf

Corter, C., \& Pelletier, J. (2010). Schools as integrated service hubs for young children and families: Policy implications of the Toronto First Duty Project. International Journal of Child Care and Education Policy, 4(2), 45-54. https://doi.org/10.1007/2288-6729-4-2-45

Creswell, J. W., \& Miller, D. L. (2000). Determining validity in qualitative inquiry. Theory Into Practice, 39(3): 124-130. https://doi.org/10.1207/s15430421tip3903_2

Cummings, C., Dyson, A., Papps, I., Pearson, D., Raffo, C., \& Todd, L. (2005). Evaluation of the full service extended schools project: End of first year report. University of Manchester.

Dani, A. A. \& de Haan, A.. (2008). Inclusive states: Social policy and structural inequalities. The World Bank.

DeMatthews, D. E., Edwards, D. B., \& Rincones, R. (2016). Social justice leadership and family engagement: A successful case from Ciudad Juárez, Mexico. Educational Administration Quarterly, 52(5), 754-792. https://doi.org/10.1177/0013161X16664006

Department for Education and Skills United Kingdom. (2004). Every child matters: Next steps. https://assets.publishing.service.gov.uk/government/uploads/system/uploads/attachment_d ata/file/272064/5860.pdf

Department of Education Northern Ireland. (2012). Extended Schools: Schools, families, communities - working together. https://www.educationni.gov.uk/sites/default/files/publications/de/extended-schools-policy-document.pdf Department of Education Northern Ireland. (2019). Extended Schools Programme annual report 2018/19. https://www.education- 
ni.gov.uk/sites/default/files/publications/education/Extended\%20Schools\%20Annual\%20R eport $\% 2018-19 \% 20$ Final.docx.pdf

Doornenbal, J., \& Kruiter, J. (2016). Twenty years of community schools in Groningen: A Dutch case study. In H. A. Lawson \& D. van Veen (Eds.), Developing community schools, Community learning centers, extended-service schools and multi-service schools (pp. 229252). Springer International Publishing. https://doi.org/10.1007/978-3-319-25664-1_9

Dryfoos, J., G. (1994). Full-service schools: A revolution in health and social services for children, youth, and families. Jossey-Bass.

Dryfoos, J. (2002). Full-Service Community Schools: Creating new institutions. The Phi Delta Kappan, 83(5), 393-399. https://www.jstor.org/stable/20440148

Durham, R. E., Shiller, J., \& Connolly, F. (2019). Student attendance: A persistent challenge and leading indicator for Baltimore's Community School Strategy. Journal of Education for Students Placed at Risk, 24(3), 218-243. https://doi.org/10.1080/10824669.2019.1615922

Epstein, J. L. (1995). School/family/community partnerships: Caring for the children we share. The Phi Delta Kappan, 76(9), 701-712. https://www.jstor.org/stable/20405436

Epstein, J. L. (2011). School, Family, and Community Partnerships: Preparing Educators and Improving Schools (2nd ed). Routledge.

Epstein, J. L., \& Becker, H. J. (1982). Teachers' reported practices of parent involvement: Problems and possibilities. The Elementary School Journal, 83(2), 103-113. http://www.jstor.com/stable/1001099

Epstein, J. L., Galindo, C. L., \& Sheldon, S. B. (2011). Levels of leadership: Effects of district and school leaders on the quality of school programs of family and community 
involvement. Educational Administration Quarterly, 47(3), 462-495. https://doi.org/10.1177/0013161X10396929

Finn-Stevenson, M., \& Zigler, E. (1999). Schools of the 21st Century: Linking childcare and education. Routledge.

FitzGerald, A. M., \& Quiñones, S. (2018). The community school coordinator: Leader and professional capital builder. Journal of Professional Capital and Community, 3(4), 272 286. https://doi.org/10.1108/JPCC-02-2018-0008

FitzGerald, A. M., \& Quiñones, S. (2019). Working in and with community: Leading for partnerships in a community school. Leadership and Policy in Schools, 18(4), 511-532. https://doi.org/10.1080/15700763.2018.1453938

Freire, P. (1970). Pedagogy of the oppressed. Bloomsbury Academic

Freire, P. (1973). Education for critical consciousness. The Seabury Press

Fuller, K., Parsons, S., MacNab, N., \& Thomas, H. (2013). How far is leadership distributed in extended services provision? Educational Management Administration \& Leadership, 41(5), 598-619. https://doi.org/10.1177/1741143213488587

Galindo, C., Sanders, M., \& Abel, Y. (2017). Transforming educational experiences in lowincome communities: A qualitative case study of social capital in a Full-Service Community School. American Educational Research Journal, 54(1S), 140S-163S. https://doi.org/10.3102/0002831216676571

Giroux, H. (1988). Teachers as intellectuals: Toward a critical pedagogy. Bergin \& Garvey Glaser, B. G., \& Strauss, A. L. (1967). The discovery of grounded theory: Strategies for qualitative research observations. Chicago, IL: Aldine Transaction. 
Goldfarb, K. P., \& Grinberg, J. (2002). Leadership for social justice: Authentic participation in the case of a community center in Caracas, Venezuela. Journal of School Leadership, 12(2), 157-173. https://doi.org/10.1177/105268460201200204

Green, T. L. (2015). Leading for urban school reform and community development. Educational Administration Quarterly, 51(5), 679-711. https://doi.org/10.1177/0013161X15577694

Green, T. L. (2018). School as community, community as school: Examining principal leadership for urban school reform and community development. Education and Urban Society, 50(2), 111-135. https://doi.org/10.1177/0013124516683997

Gruenewald, D. A. (2003). The best of both worlds: A critical pedagogy of place. Educational Researcher, 32(4). https://doi.org/10.3102/0013189X032004003

Haymes, S. (1995). Race, culture and the city: A pedagogy for Black urban struggle. State of University of New York Press

Haynes, N. M. (1996). Creating safe and caring school communities: Comer School Development Program Schools. The Journal of Negro Education, 65(3), 308-314. https://doi.org/10.2307/2967347

Henrich, C. C., Ginicola, M. M., \& Finn-Stevenson, M. (2006). The School of the 21 st Century is making a difference: Findings from two research studies. Yale University. https://medicine.yale.edu/childstudy/zigler/21c/Images/2006_IssueBrief_WebVersion_tcm 831-209575.pdf

Hernandez, F., Murakami, E. T., \& Cerecer, P. Q. (2014). A Latina principal leading for social justice: Influences of racial and gender identity. Journal of School Leadership, 24(4), 568598. https://doi.org/10.1177/105268461402400401 
hooks, b. (1994). Teaching to transgress. Routledge. https://doiorg.ezproxy.lib.ryerson.ca/10.4324/9780203700280

Hoover-Dempsey, K. V., \& Sandler, H. M. (1997). Why do parents become involved in their children's education? Review of Educational Research, 67(1), 3-42. JSTOR. https://www.jstor.org/stable/1170618

Hughes, J. N., Im, M. H., \& Allee, P. J. (2015). Effect of school belonging trajectories in grades 6-8 on achievement: Gender and ethnic differences. Journal of School Psychology, 53(6), 493-507. https://doi.org/10.1016/j.jsp.2015.08.001

Ice, C. L., \& Hoover-Dempsey, K. V. (2011). Linking parental motivations for involvement and student proximal achievement outcomes in homeschooling and public schooling settings. Education and Urban Society, 43(3), 339-369. https://doi.org/10.1177/0013124510380418

Ishimaru, A. (2013). From heroes to organizers: Principals and education organizing in urban school reform. Educational Administration Quarterly, 49(1), 3-51. https://doi.org/10.1177/0013161X12448250

Ishimaru, A. M., Torres, K. E., Salvador, J. E., Lott, J., Williams, D. M. C., \& Tran, C. (2016). Reinforcing deficit, journeying toward equity: Cultural brokering in family engagement initiatives. American Educational Research Journal, 53(4), 850-882. https://doi.org/10.3102/0002831216657178

Ishimaru, A. M. (2018). Re-imagining turnaround: Families and communities leading educational justice. Journal of Educational Administration, 56(5), 546-561. https://doi.org/10.1108/JEA-01-2018-0013

Ishimaru, A. M. (2019). From family engagement to equitable collaboration. Educational Policy, 33(2), 350-385. https://doi.org/10.1177/0895904817691841 
Ishimaru, A. M. (2020) . Just Schools: Building equitable collaborations with families and communities. Teachers College Press.

Jeynes, W. H. (2005). A meta-analysis of the relation of parental involvement to urban elementary school student academic achievement. Urban Education, 40(3), 237-269. https://doi.org/10.1177/0042085905274540

Jeynes, W. H. (2007). The relationship between parental involvement and urban secondary school student academic achievement: A meta-analysis. Urban Education, 42(1), 82-110. https://doi.org/10.1177/0042085906293818

Kerr, K., Dyson, A., Raffo, C. (2014). Education, disadvantage and place: Making the local matter. Bristol University Press

Khalifa, M. (2012). A re -new- ed paradigm in successful urban school leadership: Principal as community leader. Educational Administration Quarterly, 48(3), 424-467. https://doi.org/10.1177/0013161X11432922

Krumm, B. L., \& Curry, K. (2017). Traversing school-community partnerships utilizing crossboundary leadership. School Community Journal, 27(2), 99-120. http://www.schoolcommunitynetwork.org/SCJ.aspx

Kvale, S. (2007). Doing interviews. SAGE Publications, Ltd. https://doi.org/10.4135/9781849208963

López, G. R., Scribner, J. D., \& Mahitivanichcha, K. (2001). Redefining parental involvement: Lessons from high-performing migrant-impacted schools. American Educational Research Journal, 38(2), 253-288. https://doi.org/10.3102/00028312038002253 
Lopez, M. L., \& Stack, C. (2001). Social capital and the culture of power: Lessons from the field. In S. Saegert, J. P. Thompson, \& M. R. Warren (Eds.), Social capital and poor communities (pp. 31-59). Russel Sage Foundation.

McGill, S. (2011). 'Extended Schools': An exploration of the feelings, beliefs and intentions of parents and teachers. British Journal of Learning Support, 26(1), 4-12. https://doi.org/10.1111/j.1467-9604.2010.01469.x

Medina, M. A., Cosby, G., \& Grim, J. (2019). Community engagement through partnerships: Lessons learned from a decade of Full-service Community School implementation. Journal of Education for Students Placed at Risk, 24(3), 272-287. https://doi.org/10.1080/10824669.2019.1615923

Molnar, A., Renahy, E., O’Campo, P., Muntaner, C., Freiler, A. and Shankardass, K. (2016) Using win-win strategies to implement health in all policies: a cross-case analysis. PloS one, 11(2), 1-19. http://dx.doi.org.ezproxy.lib.ryerson.ca/10.1371/journal.pone.0147003

Muhammad, M., Wallerstein, N., Sussman, A. L., Avila, M., Belone, L., \& Duran, B. (2015). Reflections on researcher identity and power: The impact of positionality on community based participatory research (CBPR) processes and outcomes. Critical Sociology, 41(78), 1045-1063. https://doi.org/10.1177/0896920513516025

Muijs, D. (2007). Leadership in full-service extended schools: Communicating across cultures. School Leadership \& Management, 27(4), 347-362. https://doi.org/10.1080/13632430701563296

Newton, X. A., Thompson, S. R., Oh, B., \& Ferullo, L. (2017). Improving opportunities for bridging social capital: The story of a Full-Service Community School initiative at an 
alternative high school. The Educational Forum, 81(4), 418-431.

https://doi.org/10.1080/00131725.2017.1350235

O’Campo, P., Freiler, A., Muntaner, C., Gelmormino, E., Huegaerts, K., Puig-Barrachina, V., \& Mitchell, C. (2018). Resisting austerity measures to social policies: Multiple explanatory case studies. Health Promotion International, 34, 1130-1140.

https://doi.org/10.1093/heapro/day073

Patel, S., \& Corter, C. M. (2013). Building capacity for parent involvement through school-based preschool services. Early Child Development and Care, 183(7), 981-1004. https://doi.org/10.1080/03004430.2012.701625

Patel, S., Corter, C., \& Pelletier, J. (2008). What do families want? Understanding their GOALS for early childhood services. In M. Cornish (Ed.) Promising Practices for Partnering with Families In the Early Years. Information Age Publishing.

Patel, S., Corter, C., Pelletier, J., \& Bertrand, J. (2016). 'Dose-response' relations between participation in integrated early childhood services and children's early development. Early Childhood Research Quarterly, 35, 49-62. https://doi.org/10.1016/j.ecresq.2015.12.006

Pelletier, J., \& Corter, C. (2005). Toronto First Duty: Integrating kindergarten, childcare, and parenting support to help diverse families connect to schools. Multicultural Education, 13(2), 30-37.

Peterson, A., \& Durrant, I. (2013). School leaders' perceptions of the impact of extended services on families and communities: The case of one local authority. Educational Management Administration \& Leadership, 41(6), 718-735.

https://doi.org/10.1177/1741143213494190 
Quiñones, S., \& FitzGerald, A. M. (2019). Cultivating engagement with Latino children and families: Examining practices at a community school. Bilingual Research Journal, 42(3), 343-355. https://doi.org/10.1080/15235882.2019.1624280

Raffo, C., \& Dyson, A. (2007). Full service extended schools and educational inequality in urban contexts - New opportunities for progress? Journal of Education Policy, 22(3), 263-282. https://doi.org/10.1080/02680930701269160

Riester, A. F., Pursch, V., \& Skrla, L. (2002). Principals for social justice: Leaders of school success for children from low-income homes. Journal of School Leadership, 12(3), 281304. https://doi.org/10.1177/105268460201200303

Salm, T., Caswell, E., Storey, S. G., \& Nunn, A. (2016). Enhancing and Extending Full Service Community Schools in Saskatchewan, Canada: Educators Becoming Part of the Hub. In H. A. Lawson \& D. van Veen (Eds.), Developing community schools, community learning centers, extended-service schools and multi-service Schools (pp. 149-171). Springer International Publishing. https://doi.org/10.1007/978-3-319-25664-1_6

Sanders, M. (2016). Leadership, partnerships, and organizational development: Exploring components of effectiveness in three full-service community schools. School Effectiveness and School Improvement, 27(2), 157-177. https://doi.org/10.1080/09243453.2015.1030432

Shah, V. (2018a). Leadership for social justice through the lens of self-identified, racially and other-privileged leaders. Journal of Global Citizenship and Equity, 6(1). https://journals.sfu.ca/jgcee/index.php/jgcee/article/view/168

Shah, V. (2018b). Different numbers, different stories: Problematizing "Gaps" in Ontario and the TDSB. Canadian Journal of Educational Administration and Policy, 187, 31-47. https://journalhosting.ucalgary.ca/index.php/cjeap/article/view/43198 
Sheldon, S. B. (2005). Testing a structural equation model of partnership program implementation and parent involvement. The Elementary School Journal, 106(2), 171-187. https://doi.org/10.1086/499197

Sheldon, S. B. (2007). Improving student attendance with school, family, and community partnerships. The Journal of Educational Research, 100(5), 267-275. https://doi.org/10.3200/JOER.100.5.267-275

Sheldon, S. B., \& Epstein, J. L. (2002). Improving student behavior and school discipline with family and community involvement. Education and Urban Society, 35(1), 4-26. https://doi.org/10.1177/001312402237212

Sheldon, S. B., \& Epstein, J. L. (2005). Involvement counts: Family and community partnerships and mathematics achievement. The Journal of Educational Research, 98(4), 196-207. https://doi.org/10.3200/JOER.98.4.196-207

Theoharis, G. (2007). Social justice educational leaders and resistance: Toward a theory of social justice leadership. Educational Administration Quarterly, 43(2), 221-258. https://doi.org/10.1177/0013161X06293717

Theoharis, G., \& O’Toole, J. (2011). Leading inclusive ELL: Social justice leadership for English language learners. Educational Administration Quarterly, 47(4), 646-688. https://doi.org/10.1177/0013161X11401616

Toronto District School Board [TDSB]. (2005). Model Schools for Inner City Task Force report. https://www.tdsb.on.ca/Portals/0/Community/ModelSchools/InnerCityReportMay2005.pdf Toronto District School Board [TDSB]. (2008). Parent concern protocol. https://www.tdsb.on.ca/portals/0/docs/TDSB_Parent_Concern_Protocol_169.pdf 
Toronto District School Board [TDSB]. (2015) Model Schools for Inner Cities: 2014-2015 year at a glance. https://www.tdsb.on.ca/Portals/0/Community/ModelSchools/MSICYearInReview-2014-15-Web.pdf

Toronto District School Board [TDSB]. (2016). 2015-2016 year at a glance: Model Schools for Inner Cities. https://www.tdsb.on.ca/Portals/0/Community/ModelSchools/MSICYearInReview-2015-16.pdf

Toronto District School Board [TDSB]. (2019a). Toward excellence in education of Black students: Transforming learning, achievement, and well-being-leadership development. https://tdsb.on.ca/Portals/0/leadership/board_room/MYSP/Transform/Transform_Student Learning 91.pdf

Toronto District School Board [TDSB]. (2019b). Parent \& Community Engagement Office (PCEO) Report - Tuesday June 18 2019. https://www.tdsb.on.ca/Portals/0/community/Community $\% 20$ Advisory $\% 20$ committees/PI AC/2019\%2006\%2018\%20PCEO\%20Report.pdf

Toronto District School Board [TDSB]. (2020). The 2020 learning opportunity index. Toronto, ON: Toronto District School Board

Urquhart, C. (2013). Grounded theory for qualitative research: A practical guide. SAGE Publications Ltd.

Valli, L., Stefanski, A., \& Jacobson, R. (2016). Typologizing school-community partnerships: A framework for analysis and action. Urban Education, 51(7), 719-747. https://doi.org/10.1177/0042085914549366 
Van Voorhis, F., \& Sheldon, S. (2004). Principals' roles in the development of US programs of school, family, and community partnerships. International Journal of Educational Research, 41(1), 55-70. https://doi.org/10.1016/j.ijer.2005.04.005

Wholey, J. S., Hatry, H. P., \& Newcomer, K. E. (2004). Handbook of practical program evaluation (2 ${ }^{\text {nd }}$ ed.). Jossey-Bass.

Yau, M. Y., Archer, B., \& Romard, R. (2018). Model Schools for Inner Cities: A 10-year overview. Toronto District School Board. https://www.tdsb.on.ca/Portals/research/docs/reports/ResearchTodayMSIC10yearsFINAL1 4Mar18.pdf

Yau, M., Archer, B., Wong, J., Walter, S., Bonsu, V., \& Sauriol, D. (2015). Beyond 3:30: A multi-purpose after-school program for inner-city middle schools, phase IV evaluation. Toronto District School Board. https://tfss.ca/wpcontent/uploads/2017/11/B330Phase4EvalFeb19-1.pdf

Yau, M., De Jesus, S., Tam, G., \& Rosolen, L. (2015). Model Schools Paediatric Health Initiative: In-school health clinics, phase IV: Summative evaluation. Toronto District School Board. https://www.tdsb.on.ca/Portals/research/docs/reports/MSPHIPhaseIVRptFINAL15Jun16.pdf

Yau, M., Parekh, G., \& Luo, Y. C. (2013). Parenting and Family Literacy Centres : Engaging children, empowering parents. Toronto District School Board. https://www.tdsb.on.ca/Portals/research/docs/reports/RTPFLC24Apr13.pdf

Yau, M., \& Romard, R. (2016). Beyond 3:30 - A holistic after-school program for inner-city middle schools: Immediate, lifelong, and ripple effects. Toronto District School Board. 
https://www.tdsb.on.ca/Portals/0/Community/ModelSchools/B330ReseachToday22Jul16FINAL.pdf

Yin, R. K. (2009). Case study research and applications: Design and methods ( ${ }^{\text {th }}$ ed.). SAGE Publications, Inc

Yin, R. K. (2018). Case study research and applications: Design and methods (6 $6^{\text {th }}$ ed.). SAGE Publications, Inc

Yohani, S. (2011). Educational cultural brokers and the school adaptation of refugee children and families: Challenges and opportunities. Journal of International Migration and Integration. https://doi.org/10.1007/s12134-011-0229-x

Zigler, E., \& Finn-Stevenson, M. (2007). From research to policy and practice: The School of the 21st Century. American Journal of Orthopsychiatry, 77(2), 175-181.

https://doi.org/10.1037/0002-9432.77.2.175 